\title{
Fracture, Fluid and Saturation Effects on the Seismic Attributes of Hydrothermally Altered Rocks from Southern Negros Geothermal Field, Philippines
}

6

\section{David Carlo Austria ${ }^{1,2}$ and Philip M. Benson' ${ }^{1}$}

${ }^{1}$ Rock Mechanics Laboratory, School of Earth and Environmental sciences, University of Portsmouth, PO1 3QL, U.K.

${ }^{2}$ Geosciences and Reservoir Engineering Group, Energy Development Corporation, Ortigas Centre, Pasig City, Philippines

Corresponding authors: David Carlo Austria (austria.ds@energy.com.ph), Philip M. Benson (philip.benson@port.ac.uk)

Key words: geothermal, acoustic emission, seismic attributes, triaxial vessel

\section{Highlights:}

- Shear fracture development during triaxial deformation may be controlled by cutting notches to force formation of a natural fracture surface which can be accessed by miniature boreholes for fluid flow

- Elastic wave velocities and dynamic elastic parameters can be used to infer the state of material fracturing

- Acoustic emission occurs with rapid pore fluid venting under conditions similar to geothermal environments

- Extraction of fluids in a geothermal environment has a significant effect on seismicity 


\section{Abstract}

Seismic based geophysical methods are seeing increased usage in evaluating geothermal resources in order to maximize resource potential. However, interpreting geophysical data (such as velocities and dynamic modulus and fracture density/alignment) generated from geothermal reservoirs remains difficult. Here we present the results of a new laboratory study measuring seismic attributes of fresh and hydrothermally altered rocks from a Philippine geothermal field (Southern Negros Geothermal Project - SNGP) during triaxial deformation. Two types of rocks were obtained by sub-coring samples of low porosity $(\sim 1 \%)$ andesite and higher porosity $(\sim 10 \%)$ volcaniclastic samples from the SNGP. Samples were prepared with two offset drill holes to allow a natural fracture to permit fluid flow along the fracture. An embedded array of Acoustic Emission (AE) sensors allows elastic wave and induced microseismic data to be collected. We measure a significant reduction in elastic wave velocities and moduli, with the exception of Poisson's ratio, after shear fracture development. An initially pre-fractured permeability of approximately $10^{-17} \mathrm{~m}^{2}$ is measured. We find that the permeability decreases from $2.0 \times 10^{-14} \mathrm{~m}^{2}$ to lower than $7.4 \times 10^{-15} \mathrm{~m}^{2}$ as the confining pressure is increased from 5 $\mathrm{MPa}$ to $30 \mathrm{MPa}$. A concomitant increase in $\mathrm{P}$ and S-wave velocities, dynamic bulk and Young's moduli are also measured. Finally, we simulate a geothermal 'venting' situation by intentionally releasing the high pore fluid (water) pressure from 10-50 $\mathrm{MPa}$ to ambient pressure, generating a swarm of $\mathrm{AE}$ that increases in duration with higher pore pressure. We postulate that this is due to fluid phase change (liquid to gas) and movement along the natural fracture plane and damage zone.

\section{Introduction}

Inferring rock properties from geophysical data has been the subject of numerous studies for the purpose of exploring and developing energy resources (e.g. Batzle and Wang, 1992; Siratovich et al., 2014; Dupuy et al., 2015; Bonner et al., 2015). A key goal is to gain insight on the links between measurements that are hard or time-consuming to obtain (such as permeability) and geophysical data such as seismic wave velocity. However, although there is an extensive literature for petrophysical properties in reservoirs related to the hydrocarbon industry, there are fewer studies in the case of geothermal rock physics (e.g. Geraud et al., 2010; Siratovich et al., 2016; Kushnir et al., 2018). This is becoming increasingly important as the 
63 use of seismic attributes are now frequently being used to 'image' geothermal fields. A number

64 of laboratory experiments have been reported, such as on samples taken from the reservoir rock

65 of the Geysers geothermal field (e.g. Boinott et al., 1995). These data show the effects of both

66 saturation and fracturing on the $\mathrm{P}$-wave and S-wave elastic velocity, as well as the Vp/Vs ratio,

67 a very common petrophysics parameter. And, whilst this data is valuable for interpreting seismic data for geothermal exploration and development, it is also clear that additional, sitespecific, rock physics studies are needed (e.g. Siratovich et al., 2014). To this end, a number of studies have been reported that seek to measure and link key rock properties and then relate this to changes in observable seismic data. This is becoming especially important as seismic imaging techniques continue to improve and open new avenues in subsurface imaging (e.g. Julian et al., 2010; Julian and Foulger, 2010; De Siena et al., 2014; Hutchings et al., 2015).

A key tool in making new links to field data is laboratory rock physics, which allows a range of subsurface processes to be simulated under controlled conditions (e.g. Lockner et al., 1991; Ayling et al., 1995; Benson et al., 2007; Faulkner et al., 2017; Browning et al., 2016). Recent work has shown that seismic attributes of different rock types (elastic velocities and moduli) may be determined during deformation at elevated pressure and temperature (e.g. Ayling et al., 1995; Blake and Faulkner, 2015; Harnett et al., 2018; Blake and Faulkner, 2020). The initial stage of triaxial rock deformation is typically marked by increasing differential stress acting on the sample, closing micro-and macro scale cracks. This results in increasing elastic wave velocities and other attributes (Ayling et al., 1995; Harnett et al., 2018). Additional stress initiates inelastic deformation and crack formation, leading to overall decrease in seismic attributes (Ayling et al., 1995) as cracks nucleate and connect, generating acoustic emission (the laboratory analogue to tectonic earthquakes) and modifying material stiffness (Young's modulus) and Poisson's ratio. However, even though the results from these previous studies have shown the importance of seismic data on inferring rock properties, more data is needed, and in particular under geothermal conditions and using rocks from geothermal reservoirs, in order to better match geophysical data to conditions at depth.

Here we report a set of laboratory experiments from borehole samples of andesite and volcaniclastic rocks from the Southern Negros Geothermal Project. We compare elastic wave velocity and dynamic moduli to fluid flow along a freshly-generated shear fracture connecting 
fluid injection/drain ports, and with respect to initial sample porosity and post-test fracture damage. In addition, while it is important to measure seismic attributes such as $\mathrm{P}$ and $\mathrm{S}$ wave velocities, it is also important to understand the contribution of geothermal exploitation and development to seismicity. Acoustic Emission (AE) are a proven excellent analogue to field data (e.g. Lockner et al., 1991; Benson et al., 2007; Fazio et al., 2017), and can help relate field seismic methods in terms of their links to material properties (e.g. Vinciguerra et al., 2005). Using these methods, we compare and contrast the improved permeability of fractured volcanic rocks with increasing burial depth, and explore the effects of the changing magnitude of fluid flow through the fractured sample to the concomitant change in seismic attributes.

\subsection{Material, Equipment and Methods}

\subsection{Sample description and preparation}

The Southern Negros Geothermal Project (SNGP) is a high temperature, liquid dominated system situated at the western section of central Philippines (Rae et al., 2004) where magmatism is associated with the east dipping Negros Trench. This type of geothermal system has temperatures of above $225^{\circ} \mathrm{C}$ and occurs in active margins (Hochstein, 1990). The SNGP has two production sectors where extractions of high temperature fluids are carried out. These production sectors are found south of the Okoy River and north-west of the prominent volcanic peaks in the area, Mt. Talines and Cuernos de Negros (Figure 1). While production activities are concentrated at the south, fluid reinjection is conducted on the northern section of the field along the Okoy River which is controlled by the ENE-WSW trending Puhagan Fault zone (Pastoriza et al., 2018). The division of SNGP into two sectors is due to variation in reservoir pressure, injection returns and over all development strategy, with sector 1 being developed a decade earlier than sector 2 (Malate et al., 2008).

The routine drilling activities at the SNGP have allowed direct access to subsurface rock units, from which a number of sub-cores were taken in order to examine seismic attributes with changing pressure conditions. This provides a valuable set of advantages in the sense that these samples are retrieved from depth, with relatively few studies having reported data using rocks taken directly from a geothermal reservoir (e.g. Geraud et al., 2010; Kushnir et al., 2018). Two sample types were utilized in this study. Firstly, a volcaniclastic rock (SNV) described as having 
126 a very fine-grained matrix and clasts consisting of angular to sub angular lithic fragments and 127 plagioclase and amphibole minerals that are identifiable under the petrographic microscope.

128 Devitrification process appears to have occurred in SNV samples, replacing volcanic glasses

129 by zeolites occurring as radial fans in amygdales. The lithic fragments are found to consist of

130 porphyritic andesite and volcaniclastic rocks. SNV is marked by presence of significant void

131 spaces and fragmented texture. The second type of sample is a porphyritic andesite (SNA) that

132 exhibits fractures filled with silica/quartz. SNA samples consist mainly of pyroxene and

133 plagioclase phenocrysts wherein some of the plagioclase crystals were partially replaced by

134 hydrous minerals such as kaolinite and are partially embayed. Both types of sample belong to

135 the Southern Negros Formation which is described as a sequence of polymictic volcaniclastic

136 breccia and coherent volcanic rocks (Rae et al., 2004). The Southern Negros Formation is found

137 to exhibit alteration assemblage from low-temperature illite alteration, consisting mainly of

138 illite and or smectite, to high-temperature propylitic alteration near the upflow zone, composed

139 mainly of secondary mineral epidote (Rae et al., 2003).

140

141 Aside from rock type (composition and texture), SNV and SNA exhibit significant

142 differences in porosity and density which were acquired with the use of hydrostatic weighing 143 and helium pycnometer on a number of disc samples cut from the cylindrical samples subjected 144 to the tri-axial experiment. SNV samples have porosities ranging from 10 to $13 \%$ and bulk 145 densities of 2.3 to $2.4 \mathrm{~g} / \mathrm{cm}^{3}$. Conversely, SNA samples have lower porosity of $<1 \%$ and higher 146 bulk density of $2.7 \mathrm{~g} / \mathrm{cm}^{3}$. The sample properties are tabulated in Table 1. 


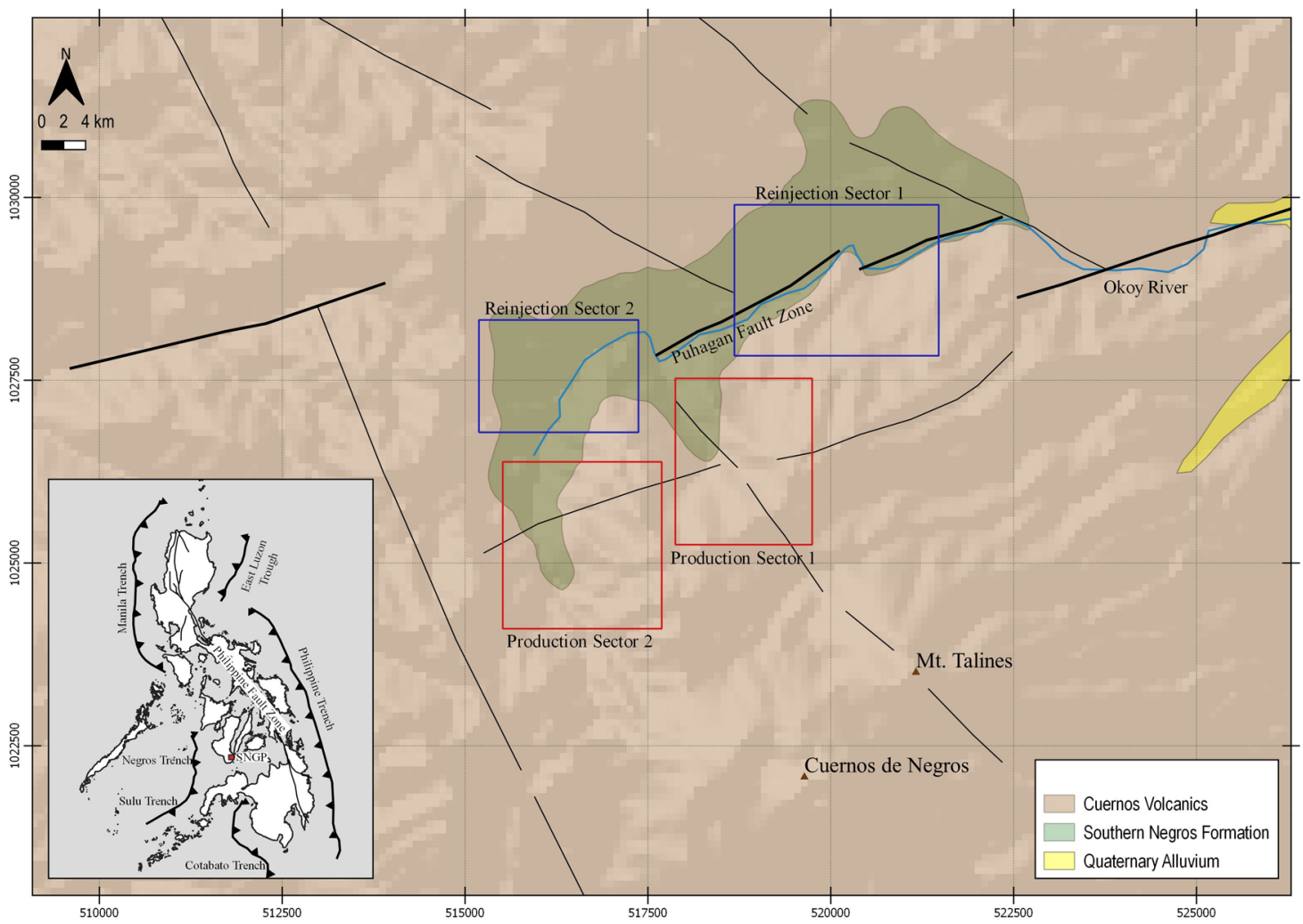

Figure 1. Simplified geologic map of the Southern Negros Geothermal Field showing the production (red rectangles) and reinjection (blue rectangles) sectors (modified after Pastoriza et al., 2018; Rae et al., 2003). Also shown are the key lineaments (black lines) identified by Pastoriza et al., (2018) and the Okoy River (light blue line). The tectonic map of the Philippines (inset) shows the location of the SNGP with respect to major geologic structures in the area (modified after Aurelio et al., 2013). SRTM data taken from Jarvis et al., (2008).

155 Table 1. Porosity, density and sample type of SNGP samples.

\begin{tabular}{lllll}
\hline \multirow{2}{*}{ Sample Type } & Sample Name & Porosity $(\%)$ & Density $\left(\mathbf{g} / \mathbf{c m}^{3}\right)$ & Rock Type \\
& AA4-1 & 0.1 & 2.7 & \\
\multirow{3}{*}{ AA4 (SNA) } & AA4-2 & 0.1 & 2.7 & Porphyritic \\
& AA4-3 & 0.1 & 2.7 & Andesite \\
& AA4-4 & 0.1 & 2.7 & \\
\hline \multirow{2}{*}{ AA3 } & AA3-1 & 0.6 & 2.68 & Porphyrictic \\
& AA3-2 & 0.6 & 2.68 & andesite \\
\hline \multirow{2}{*}{ AA1 } & AA1-1 & 5.7 & 2.55 & Porphyrictic \\
& AA1-2 & 5.7 & 2.55 & andesite \\
\hline \multirow{2}{*}{ AA5 } & AA1-3 & 5.7 & 2.55 & Highly Altered \\
& AA5-1 & 10.6 & 2.42 & volcaniclastic rock \\
\hline \multirow{2}{*}{ AA6 (SNV) } & AA6-1 & 12.6 & 2.32 & Volcaniclastic \\
& AA6-2 & 12.6 & 2.32 & rock \\
\hline
\end{tabular}


Cylindrical core samples of $100 \mathrm{~mm}$ long and $40 \mathrm{~mm}$ diameter were prepared using a hollow diamond core drill and diamond-grinding wheel to ensure sample ends were flat and parallel to within $0.01 \mathrm{~mm}$. An important aspect of the project is to study the evolution of fracture

161 permeability along a natural fracture plane (damage zone) resulting from the application of a

162 principal stress. This has the advantage of being more representative of the types of undulating

163 surfaces seen in nature, compared to pre-cut plane often utilized by previous studies (e.g.

164 McLaskey and Lockner, 2014; Faulkner et al., 2017; Passelègue et al., 2016). The disadvantage

165 of this, however, is the more difficult preparation and ensuring the fluid flows along the developed shear plane. To achieve this, two offsets notches were cut across the diameter of the sample at the side on both ends (Figure 2) to promote a connecting $30^{\circ}$ shear fracture. This natural fracture was accessed by drilled holes at both ends of the sample to intersect the shear plane (Figure 2).
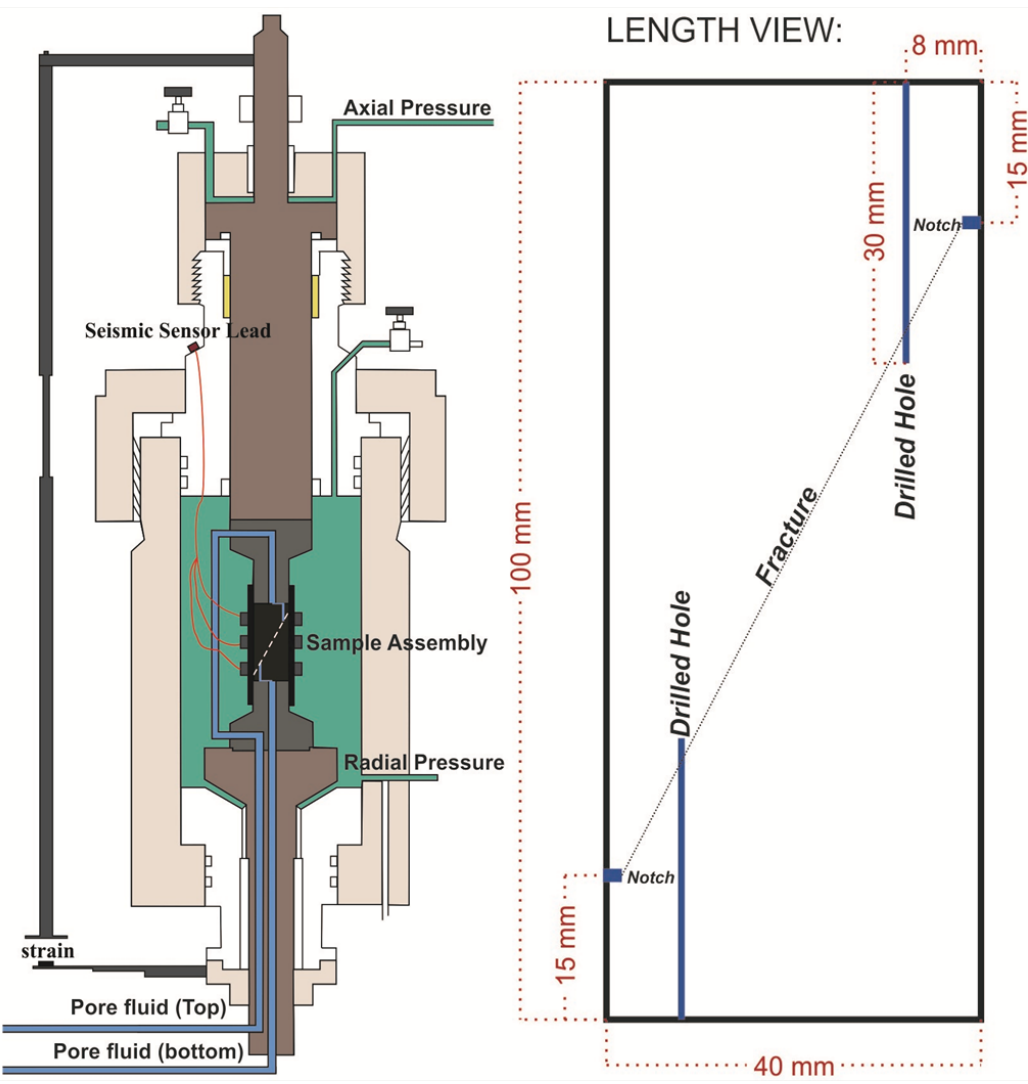

ISOMETRIC VIEW:

Figure 2. Schematics of the triaxial deformation equipment utilized for the study (modified after Benson et al., 2019) and drill core setup using pre-cut notches and boreholes to promote formation of a natural fracture and damage zone connecting the 


\subsection{Shear fracture development}

A conventional triaxial vessel (Sanchez Technologies) was used to fracture the samples. This consists of a $100 \mathrm{MPa}$ pressure chamber fitted with an electronically compensated servocontrolled axial piston capable of providing $680 \mathrm{MPa}$ principal stress using a sample diameter of $40 \mathrm{~mm}$ (Figure 2). Confining and axial pressures are regulated by precision piston pumps using high-flash point oil as pressurising medium. The vessel is additionally fitted with two servo-controlled precision pumps to independently introduce a (fixed) pore fluid pressure to each end of the rock specimen, providing upstream and downstream fluids pressures and concomitant fluid volume change. Samples are encapsulated in an engineered rubber (Nitrile) jacket fitted with 18 ports for acoustic emission (AE) and other sensors, and to separate the water-saturated sample from the confining oil. The AE sensors are custom-built miniature AE sensors consisting of an aluminium casing fitted with a waveguide, a $3.5 \mathrm{~mm}$ thick LeadZirconate-Titanate (PZT) piezoelectric ceramic with $1 \mathrm{MHz}$ resonant frequency, and backed with a short tungsten rod to reduce waveform resonance (Fazio et al., 2017). The sensors convert incoming mechanical signals to voltages that are then amplified by between 30 to 70 $\mathrm{dB}$ before being fed into two independent $\mathrm{AE}$ recorders for analysis. Axial strain data from the sample were acquired using an Eddy Displacement System. This is an external non-contact transducer system attached to a stationary ring assembly at the bottom of the tri-axial vessel which measures the distance to three steel targets attached to the (moving) top piston ring to measure average displacement. Radial strain is acquired through the use of internal Linear Variable Differential Transformer directly mounted on a cantilever attached to the rock sample via 4 jacket ports (Gehne et al., 2019).

Two types of experiments are performed (Figure 3). Firstly (Fig. 3A), a triaxial deformation experiment is conducted $\left(\sigma_{1}>\sigma_{2}=\sigma_{3}\right)$ at elevated confining pressure (Pc) to generate a shear fracture plane, followed by lowering of differential stress to re-establish isostatic conditions $\left(\sigma_{1}=\sigma_{2}=\sigma_{3}\right)$. Once achieved, the effective pressure (Pp-Pc) is increased stepwise with water flow rate across the drilled injector/receiver ports and elastic wave velocity measured at each step. This is repeated with stepwise decreasing effective pressure. Secondly (Fig. 3B), the same type of deformation experiment is performed. Then, once a target pore fluid pressure is reached, the vessel and assembly is heated to a target temperature of $175^{\circ} \mathrm{C}$. A fast-acting valve is then 

and thus to record the effect of fluid pressure release and fluid-mechanical effects (from liquid to a steam/gas mixture) on the recorded fluid-pressure and $\mathrm{AE}$, which are recorded at the same

211 high sampling rates to ensure no information is lost and to ensure no timing errors between the 212 pore fluid pressure (venting data) and the AE data recorders.
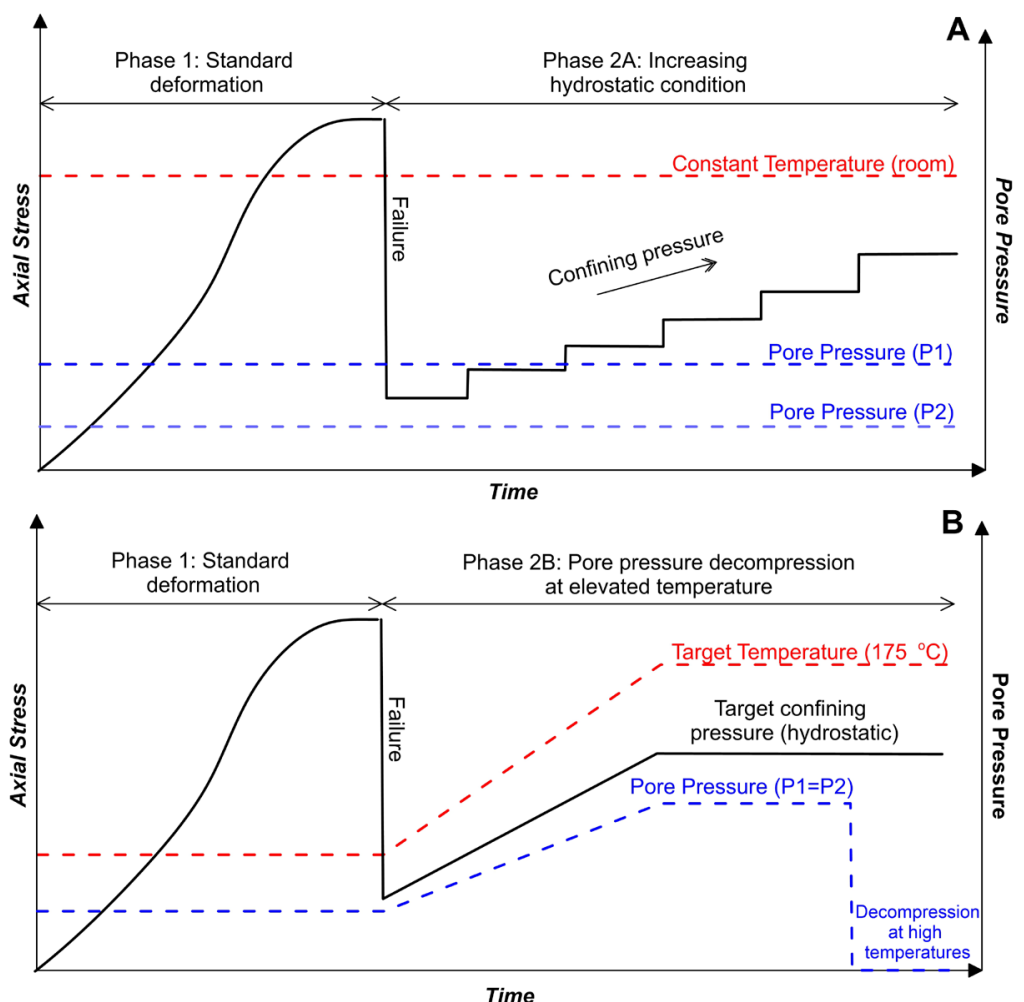

Figure 3. Schematic axial stress-time plots showing the two types of experiments conducted for this study. Panel (A) shows the post-failure stepwise increase in confining pressure under hydrostatic conditions where data is acquired at each step. Panel (B) shows the same initial fracture development followed by the procedure for pore pressure decompression at high temperature conditions.

Table 2. Sample dimensions and parameters used during deformation

\begin{tabular}{lll}
\hline Sample Type & Dimension $(\mathrm{mm})$ & Parameters during deformation
\end{tabular}




\begin{tabular}{|c|c|c|c|c|c|}
\hline & $\begin{array}{c}\text { Sample } \\
\text { Name }\end{array}$ & (height $\mathrm{x}$ diameter) & $\begin{array}{l}\text { Pore fluid } \\
\text { pressure (MPa) } \\
\text { (P2 and P1) }\end{array}$ & $\begin{array}{l}\text { Confining } \\
\text { Pressure } \\
\text { (MPa) }\end{array}$ & $\begin{array}{l}\text { Strain } \\
\text { rate }\left(s^{-1}\right)\end{array}$ \\
\hline \multirow{4}{*}{ AA4 (SNA) } & AA4-1 & $100.29 \times 40.15$ & 0.8 and 1.3 & 6.1 & $3 \times 10^{-6}$ \\
\hline & AA4-2 & $100.31 \times 40.13$ & 0.8 and 1.3 & 6.1 & $3 \times 10^{-6}$ \\
\hline & AA4-3 & $100.45 \times 40.15$ & 0.8 and 1.3 & 6.1 & $3 \times 10^{-6}$ \\
\hline & AA4-4 & $100.61 \times 40.14$ & 0.8 and 1.3 & 6.1 & $3 \times 10^{-6}$ \\
\hline \multirow{2}{*}{ AA3 } & AA3-1 & $100.07 \times 40.14$ & 0.8 and 1.3 & 6.1 & $3 \times 10^{-6}$ \\
\hline & AA3-2 & $100.47 \times 40.16$ & 0.8 and 1.3 & 6.1 & $3 \times 10^{-6}$ \\
\hline \multirow{3}{*}{ AA1 } & AA1-1 & $100.68 \times 40.15$ & 0.8 and 1.3 & 6.1 & $3 \times 10^{-6}$ \\
\hline & AA1-2 & $100.33 \times 40.17$ & 0.8 and 1.3 & 6.1 & $3 \times 10^{-6}$ \\
\hline & AA1-3 & $100.09 \times 40.14$ & 0.8 and 1.3 & 6.1 & $3 \times 10^{-6}$ \\
\hline AA5 & AA5-1 & $100.04 \times 40.15$ & 0.8 and 1.3 & 6.1 & $3 \times 10^{-6}$ \\
\hline \multirow{3}{*}{ AA6 (SNV) } & AA6-1 & $100.16 \times 40.13$ & 0.8 and 1.3 & 6.1 & $3 \times 10^{-6}$ \\
\hline & AA6-2 & $100.32 \times 40.15$ & 0.8 and 1.3 & 6.1 & $3 \times 10^{-6}$ \\
\hline & AA6-3 & $100.03 \times 40.17$ & 0.8 and 1.3 & 6.1 & $3 \times 10^{-6}$ \\
\hline
\end{tabular}

\subsection{Fluid flow \& permeability}

During phase (2A) of the experiment as shown above, the steady-state flow method is used to calculate an 'effective' permeability (e.g. Gehne and Benson, 2018) along the fracture damage zone. The fluid flow rate is directly known from the change in pump volume with time, which is measured stepwise with increasing confining pressure simulating burial depth. At each effective pressure steady state flow is then ensured by allocating a minimum of 10 minutes. This allows time for fluids to be expelled or imbibed by void spaces, and re-establishes a steady flow condition through the fractured sample with upstream and downstream pressure pumps exhibiting similar but opposite flow rate values (acting as a check for leaks in the system). The resulting flow rate from the pressure pumps were then averaged and input into Darcy's equation to calculate and model the permeability of the fractured zone:

$$
k=\frac{Q L \eta}{(W H)\left(P-P^{\prime}\right)}
$$

where: $\mathrm{k}$ is effective permeability $\left(\mathrm{m}^{2}\right)$

$\mathrm{Q}$ is volumetric flow rate $\left(\mathrm{m}^{3} / \mathrm{s}\right)$

$\mathrm{L}$ is length of the fracture zone $(\mathrm{m})$

$\eta$ is the fluid viscosity at room temperature $\left(8.9 \times 10^{-4} \mathrm{~Pa} . \mathrm{s}\right)$

$\mathrm{W}$ is the width of the fracture zone $(\mathrm{m})$ 
$\mathrm{H}$ is the thickness of the fracture zone $(\mathrm{m})$

$\mathrm{P}$ is the entry pore pressure $(\mathrm{Pa})$

$\mathrm{P}^{\prime}$ is the exit pore pressure $(\mathrm{Pa})$

Unlike when considering fluid flow in an entire porous cylinder (conduit or pipe) here we apply Darcy's equation to a fracture zone which we take as a rectangular prism with known dimensions. The length and width are set following the dimension of the notches, while the height (or thickness of the fracture zone) is modelled at different values ranging from 1 to 10 $\mathrm{mm}$. These result in a range of 'effective' permeability in the deformed sample at each confining pressure. Other parameters are recorded directly by the instrument including the fluid pressures and volume change with time.

\subsection{Acoustic Emission and elastic-wave velocities}

Acoustic Emission is generated from natural crack formation and fracture development while the samples are undergoing deformation, and is the laboratory proxy to field scale earthquakes (e.g. Benson et al., 2007). In the setup used here, AE data is recorded continuously on two independent $\mathrm{AE}$ recorders that operate simultaneously, taking their input from the same array of 12 AE sensors after pre-amplification of the signal by 30-70 db (selectable). The first system (ITASCA-Image Milne) records a discrete waveform time range across all 12-channels when any single channel exceeds a set threshold voltage of $100 \mathrm{mV}$ in a window of $200 \mathrm{us}$. The second system (ITASCA-Image Richter) records all 12 channels regardless if there are AEs or not. This data type is capable of capturing more acoustic emissions as the signal processing is performed after the experiment. Unlike the triggered data, this allows the continuous data to be 'harvested' post-test using more stringent criterion. In this way, the continuous data processing procedure filters out noise and improves the overall quality of harvested events. Both systems operate at $10 \mathrm{MHz}$ and are described in Gehne et al. (2019).

Active surveys for elastic-wave velocity determination are taken by pulsing a high voltage spike through each of the same 12 sensors in sequence, controlled and timed using a dedicated Pulser Interface Unit (PIU) to permit stacking of 32 traces per sensor to improve signal to noise (similar to field reflection seismic acquisition). As each sensor pulses, the remaining 11 sensors receive, allowing signal propagation in different directions (e.g. Harnet et al., 2018). Arrival 
285 times of both $\mathrm{P}$ and $\mathrm{S}$ waves after propagation are recorded on each sensor (of known location)

286 allowing velocity to be calculated using the time-of-flight method (Birch, 1960). The dynamic 287 elastic properties are then derived using the velocity data following the equations below.

where: Vp is P-wave velocity $(\mathrm{km} / \mathrm{s})$

$$
\text { Bulk Modulus (B) }=\rho\left(\mathrm{V}_{P}^{2}-\frac{4}{3} V_{S}^{2}\right)
$$

\section{3.1. Elastic wave velocities of SNGP samples}

297 The SNA samples have initial (at an isostatic pressure of $5 \mathrm{MPa}$ ) P-wave and S-wave velocities 298 of $5340 \mathrm{~m} / \mathrm{s}$ and $2430 \mathrm{~m} / \mathrm{s}$ respectively (Figure 4). As the deformation proceeds (phase 1) the 299 velocities increase until approximately 3500s with the P-wave velocity reaching a maximum of $3005700 \mathrm{~m} / \mathrm{s}$ before sample failure at approximately 4000s. The S-wave velocity increases to a 301 maximum of approximately $2500 \mathrm{~m} / \mathrm{s}$ at 3000s after which velocity starts to decrease (to 2350 $302 \mathrm{~m} / \mathrm{s}$ just prior to sample failure). After failure, axial stress is intentionally lowered to re-establish 303 an isostatic stress state (approximately 4500s) with P-wave and S-wave velocities of $4250 \mathrm{~m} / \mathrm{s}$ 304 and $1500 \mathrm{~m} / \mathrm{s}$ respectively. Subsequently, in phase $2 \mathrm{~A}$ of the experiment, confining pressure is 305 increased stepwise. P-wave velocity increases to $4800 \mathrm{~m} / \mathrm{s}$ at $6200 \mathrm{~s}$ (10 MPa confining pressure) followed by a roughly linear increase to $5100 \mathrm{~m} / \mathrm{s}$ at 12000s (30 MPa). For S-wave

307 data, an approximate linear increase in velocity is measured after failure to $1800 \mathrm{~m} / \mathrm{s}$ at $12000 \mathrm{~s}$ 308 (30 MPa). Flow rate decreases exponentially during this time from $7.7 \mu \mathrm{l} / \mathrm{s}$ to $0.3 \mu \mathrm{l} / \mathrm{s}$. 

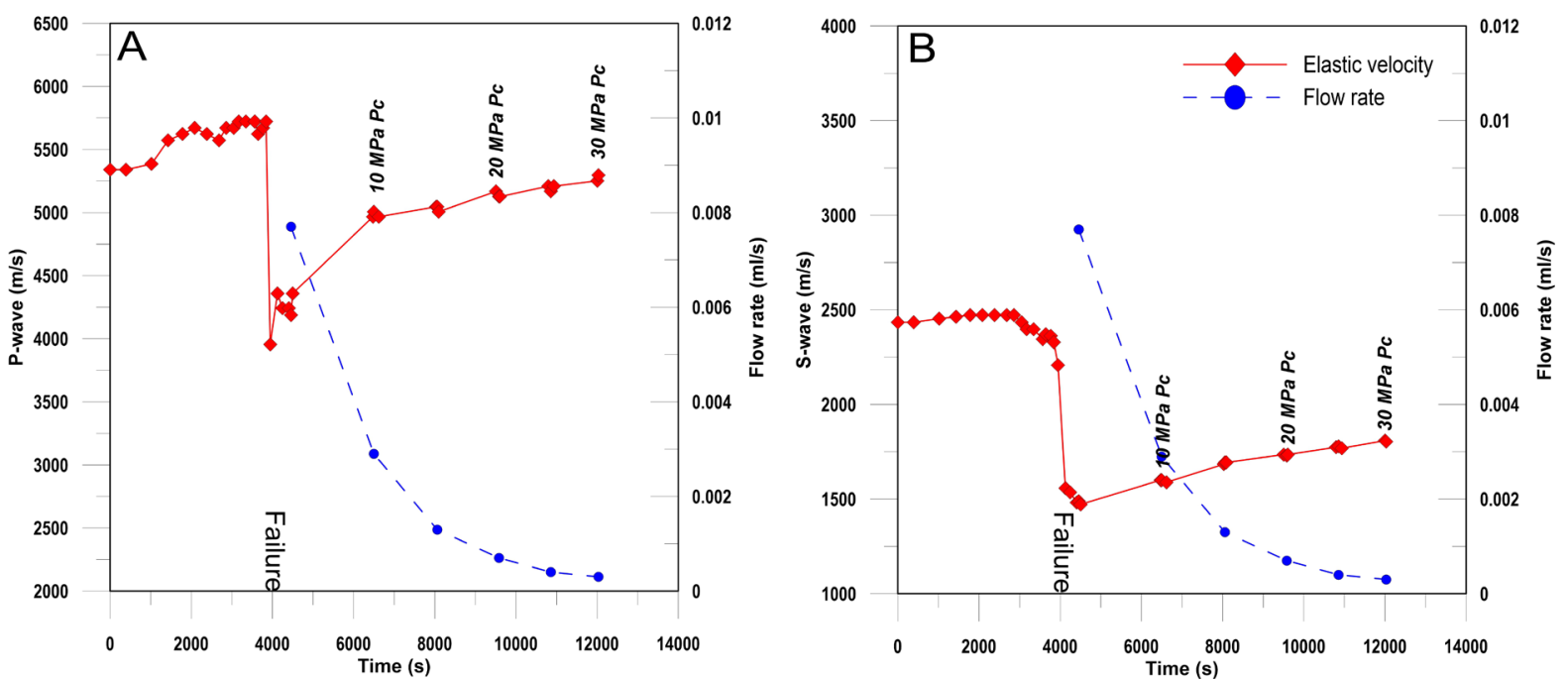

Figure 4. P-wave (panel A) and S-wave (Panel B) elastic velocities (solid lines) in SNA undergoing fracture formation and damage zone development. Flow rate data (dashed lines) acquired after failure is also plotted as a function of stepwise increasing effective pressure (annotated).

Figure 5 uses P-wave and S-wave data to calculate dynamic Poisson's ratio (Fig. 5A), Bulk modulus (Fig. 5B) and Young's modulus (Fig. 5C) during the same time period of deformation and fracture. The resulting initial values are $0.37,78 \mathrm{GPa}$ and $35 \mathrm{GPa}$ respectively. At the moment of failure, all properties exhibit a significant permanent reduction except for Poisson's ratio which recovers quickly to a value of approximately 0.43 , higher than pre-failure modulus. Bulk modulus decreases to $40 \mathrm{GPa}$ whereas the Young's modulus decreases to $15 \mathrm{GPa}$. Both

321 bulk and Young's modulus then exhibit increasing trends (recovery) as confining pressure is 322 increased stepwise (4000 to 12000 s) reaching 75 and $23 \mathrm{GPa}$ respectively at the maximum 323 30MPa effective pressure. However, neither moduli re-achieve pre-failure levels. Conversely, 324 Poisson's ratio exhibits a decreasing trend as a response to isostatic stress increase after failure, 325 remaining at above 0.41 . 

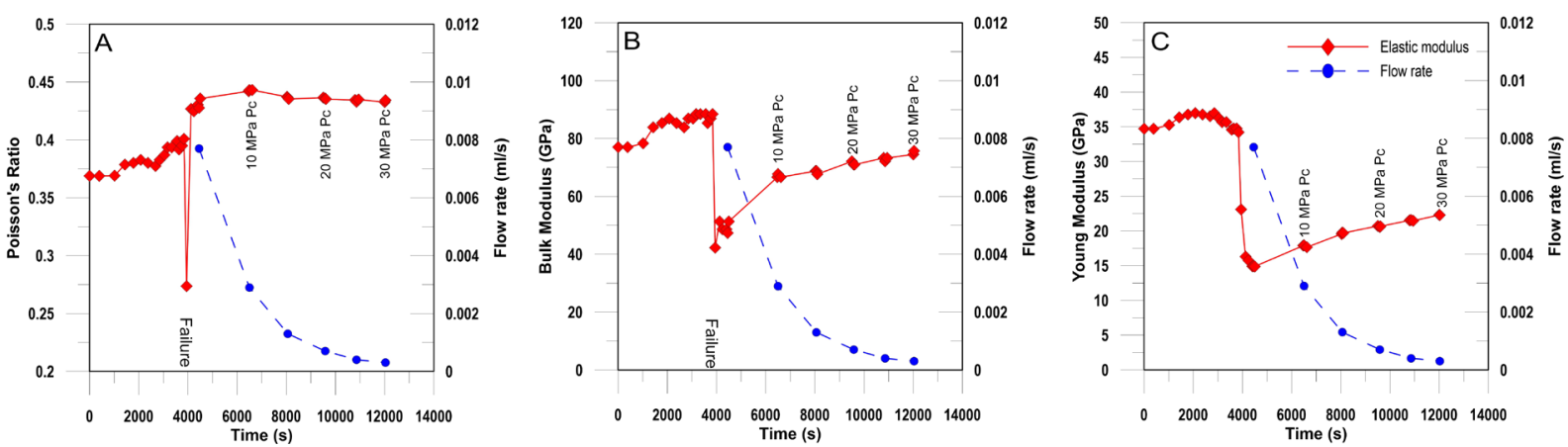

Figure 5. Dynamic modulus evolution (red) in the SNA while undergoing deformation and fracture development. Poisson's ratio (panel A), bulk modulus (panel B) and Young's modulus (panel C) are plotted with flow rate data (blue) acquired after failure (at approximately 4000s) and following increase in confining pressure (PC).

The low density $\left(<2.45 \mathrm{~g} / \mathrm{cm}^{3}\right)$, high porosity (10-12\%) SNV samples exhibit lower elastic wave velocities and seismic attributes. Figure 6 shows the initial P-wave and S-wave velocities of $2500 \mathrm{~m} / \mathrm{s}$ and $1450 \mathrm{~m} / \mathrm{s}$ respectively. In common with the SNA data, both velocities increase with time until failure at approximately $1800 \mathrm{~s}$, reaching $2800 \mathrm{~m} / \mathrm{s}$ for P-wave velocity and 1650 $\mathrm{m} / \mathrm{s}$ for S-wave. However, a few notable differences are also evident compared to the SNA elastic wave velocities. Rather than a sharp decrease, the reduction in elastic wave velocity occurs more gradually, starting from maximum values at approximately 1900s that coincides with peak differential of approximately $60 \mathrm{MPa}$. P-wave velocity decreases to approximately $2400 \mathrm{~m} / \mathrm{s}$ while S-wave velocity decreases to $1400 \mathrm{~m} / \mathrm{s}$ over approximately $600 \mathrm{~s}$ (failure). After failure at 2500s, differential stress is lowered to achieve isostatic conditions at $5 \mathrm{MPa}$ confining pressure for phase $2 \mathrm{~A}$ of the experiment. As pressure is increased stepwise to $30 \mathrm{MPa}(10800 \mathrm{~s})$, P-wave velocity reaches $3000 \mathrm{~m} / \mathrm{s}$, higher than its pre-failure peak (Figure 6A) with S-wave increasing to $1500 \mathrm{~m} / \mathrm{s}$ in an approximately linear fashion. Fluid flow though the fracture decreases during phase 2 from $10.2 \mu \mathrm{l} / \mathrm{s}$ to $5 \mu \mathrm{l} / \mathrm{s}$. 

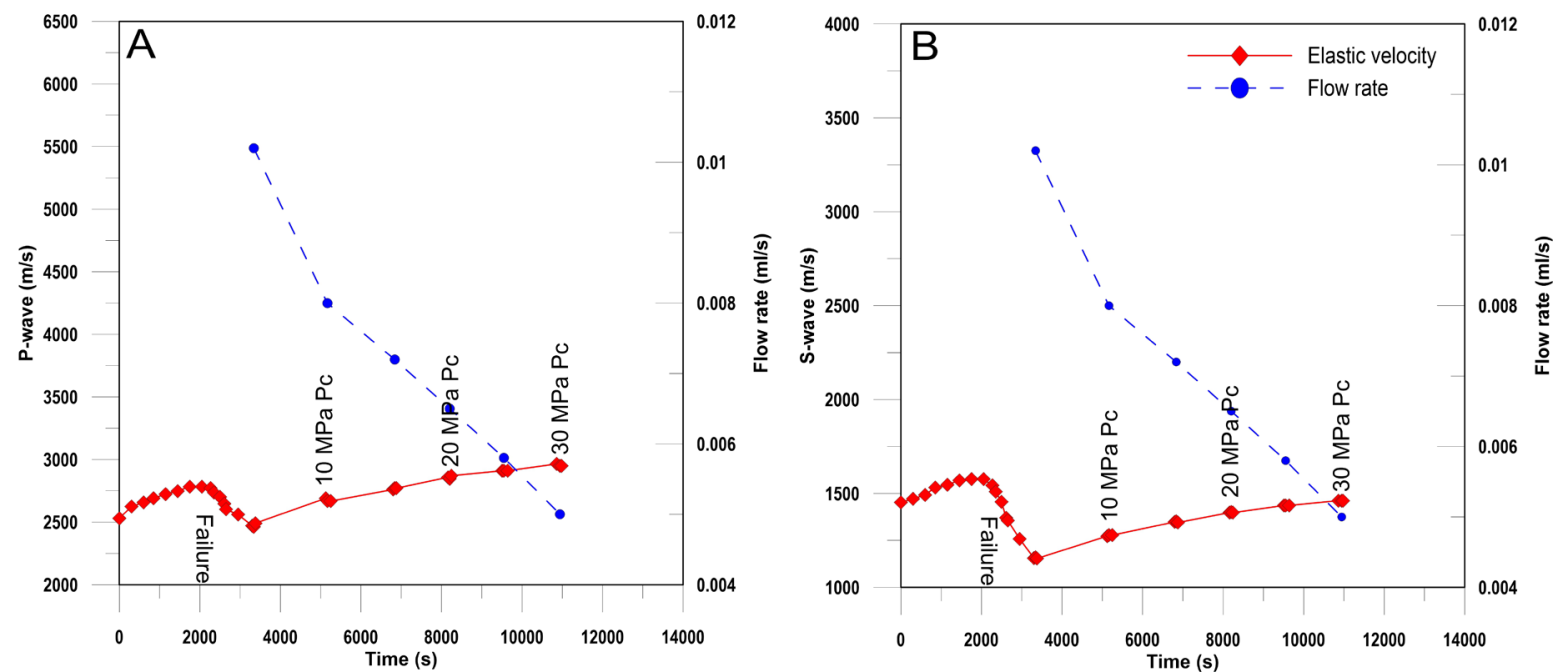

Figure 6. P-wave (Panel A) and S-wave (Panel B) elastic wave velocities showing reduction as a response to crack propagation and fracture development (red) in SNV. Flow rate data (blue) exhibits decreasing trend with increasing confining pressure post failure.
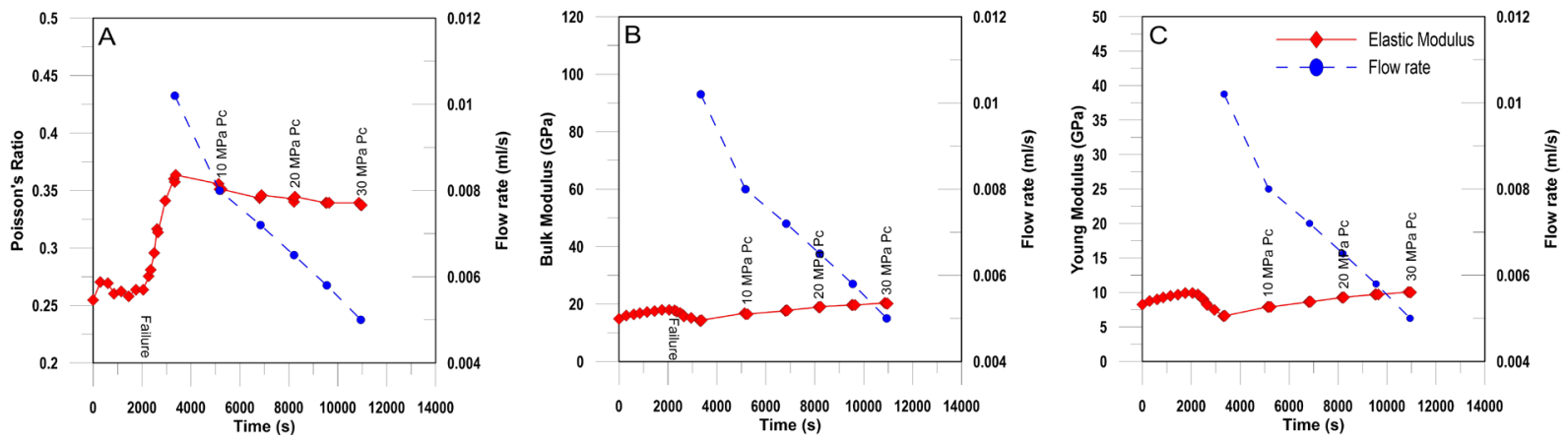

Figure 7. Dynamic moduli of the porous and low density volcaniclastic rock (SNV) while undergoing deformation and fracture development. Flow rate data is plotted in blue. Poisson's ratio (A) showing opposite response to failure compared with bulk modulus (B) and Young's modulus (D).

Using the elastic wave data for SNV (Figure 6) to calculate Poisson's ratio (Fig. 7A), Bulk Modulus (Fig. 7B) and Young's modulus (Fig. 7C) yields initial values of 0.27, $15 \mathrm{GPa}$ and 8 $\mathrm{GPa}$, respectively. The values increase with sample strain (time from 0 to approximately 2000s) with the exception of Poisson's ratio which stays approximately constant (Fig. 7A). At peak differential stress, bulk modulus reaches $18.5 \mathrm{GPa}$ while Young's modulus increases to $10 \mathrm{GPa}$. The most sensitive parameter to the changing stress state is Bulk modulus, which decreases from 18.5 MPa to approximately $15 \mathrm{MPa}$ at the point of failure (2500s). During the same period of time Young's modulus decreases from 10 to $8 \mathrm{GPa}$. As the isostatic stress state is re-achieved (3000s) these values further change to is $0.35,14.5 \mathrm{GPa}$ and $6 \mathrm{MPa}$ respectively (Fig. 7A-C). Finally, Poisson's ratio decreases only slightly to 0.34 as the effective pressure increases stepwise from 5 to $30 \mathrm{MPa}$. However, the remaining parameters all increase linearly with 
366 increasing effective pressure to 20 and $9.5 \mathrm{GPa}$ for Bulk and Young's modulus respectively,

367 except for the first step in each case $(2500 \mathrm{~s}-3500 \mathrm{~s})$.

\subsection{Fluid-flow data of SNGP samples}

The pre-deformation fluid flow (permeability) of intact (i.e. unfractured) SNA was too low to be measured in our setup via the steady-state-flow method, suggesting that permeability is lower than approximately $10^{-20} \mathrm{~m}^{2}$ or $10^{-4} \mu \mathrm{l} / \mathrm{s}$, even for integrating flow volume over several days. During the post-failure stage of the SNGP experiments, a differential fluid pressure was applied to pair of fluid ports (Fig. 2) to generate fluid flow. For SNA samples, a flow-rate of $7.7 \mu 1 / \mathrm{s}$ was initially measured at $5 \mathrm{MPa}$ confining pressure, decreasing with each increase in effective pressure $0.3 \mu \mathrm{l} / \mathrm{s}$ at $30 \mathrm{MPa}$ (Fig. 4). For SNV samples which have higher natural (background) porosity, the fluid flow was far higher. At $5 \mathrm{MPa}$ immediately after sample fracture, a flow rate of $10.2 \mu \mathrm{l} / \mathrm{s}$ was measured, decreasing in steps with increasing effective pressure to $5 \mu \mathrm{l} / \mathrm{s}$ (Fig. 6). This compares to a background flow rate of $6.72 \mu \mathrm{l} / \mathrm{s}$ (equivalent to a permeability of $10^{-17}$ $\mathrm{m}^{2}$ across a homogeneous cylinder of $4 \mathrm{~cm}$ diameter) before deformation (unfractured sample)

381 at $5 \mathrm{MPa}$ effective pressure.

\subsection{Acoustic Emission stimulation at high temperature}

Select experiments using the low porosity samples were repeated at high temperature (175 ${ }^{\circ} \mathrm{C}$ ) using phase $2 \mathrm{~B}$ of the protocol described earlier (Figure 3) at three confining pressure conditions (10 MPa, $20 \mathrm{MPa}$, and $50 \mathrm{MPa})$. At a confining pressure of $10 \mathrm{MPa}$, and an initial pore fluid venting pressure of $5 \mathrm{MPa}$, we record an increase in AE reaching 250 hits at the point of pressure release (Fig. 8). Here, the AE hit rate increases rapidly from zero to 250 counts/0.1 $\mathrm{ms}$ at $128.5 \mathrm{~s}$ (the moment of fluid pressure release). The count-rate then briefly decreases only to increase again starting at $129 \mathrm{~s}$. During this time $(128.5-129.5 \mathrm{~s})$ we note the pore pressure remains largely constant at $0.8 \mathrm{MPa}$. This is followed by a final increase in AE at 130-131s which coincides with the final decrease in pore pressure to ambient conditions. Throughout the venting process, axial strain remains at constant level suggesting minimal sample movement. 

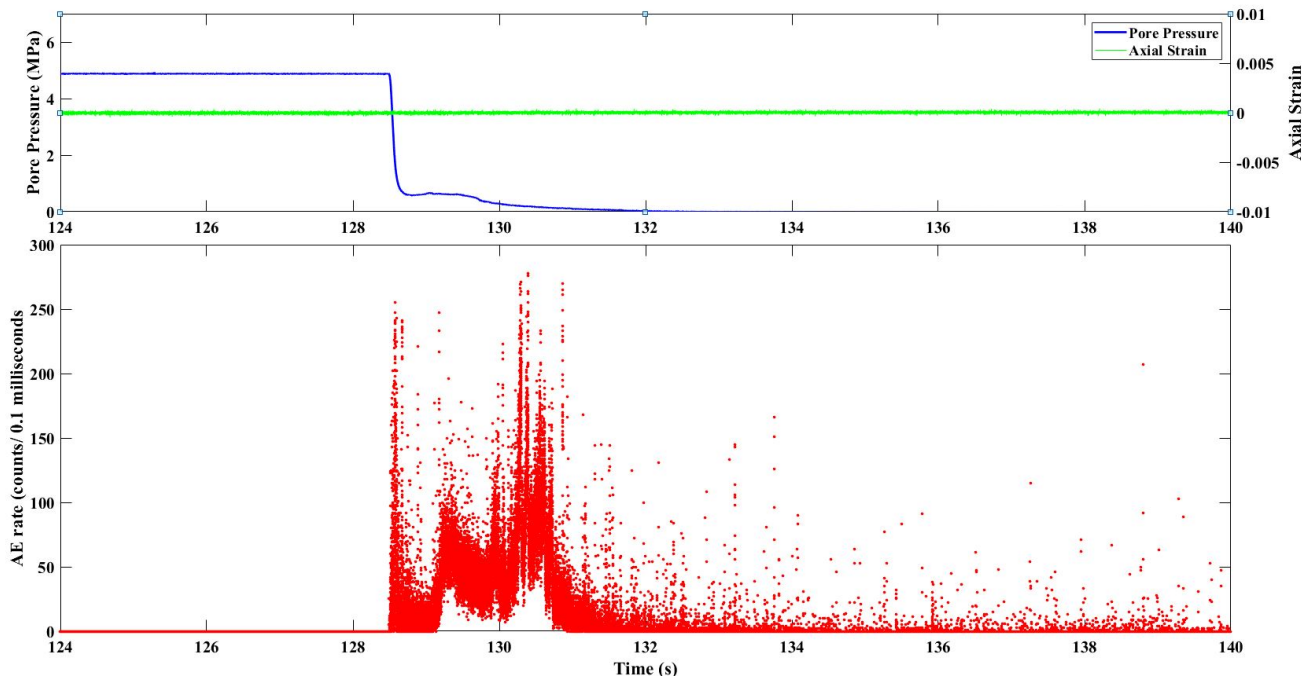

Figure 8. Spike in acoustic emission at the point of pore fluid decompression ( 128.5s) for confining pressure of $10 \mathrm{MPa}$ and pore fluid pressure of $5 \mathrm{Ma}$.

Data for fluid venting at $20 \mathrm{MPa}$ confining pressure and a pore fluid pressure of $10 \mathrm{MPa}$ are shown in figure 9. At the onset of pore pressure release (141.5s), a swarm of AE is recorded reaching 100 counts/ 0.1 milliseconds before subsiding to between 20-50 counts/s, during which time the pore pressure remains at just under $1 \mathrm{MPa}(141.5-142.5 \mathrm{~s})$. After this, an emergent increase in $\mathrm{AE}$ rate is recorded up to nearly 350 counts/ 0.1 milliseconds, accompanied by pore pressure reduction to zero (143s). Measurement of axial strain data does not show any movement, again suggesting that the fluid venting and the rock-fluid coupling solely generate the AE output during the pressure release, combined with the phase change of liquid water to a water/steam mixture, similar to the data and protocols reported in Benson et al. (2014) and Fazio et al. (2017). 
409

410

411

412

413

414

415

416

417

418

419

420

421

422

423

424
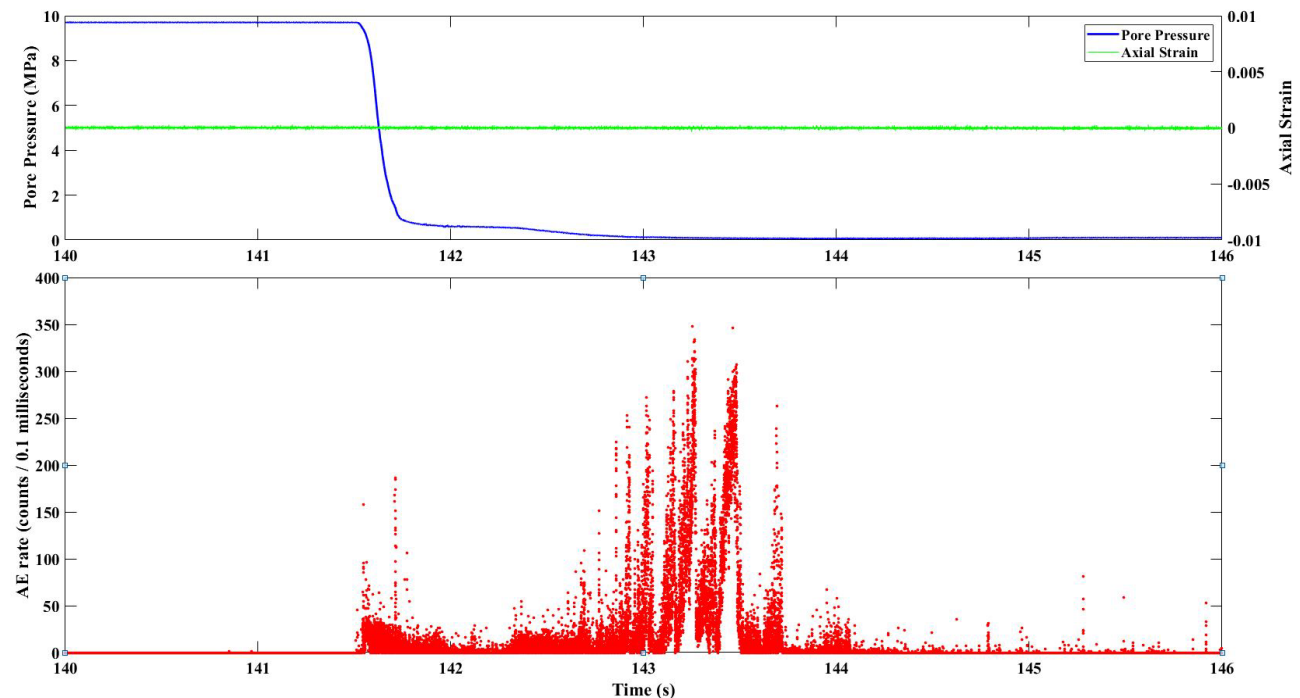

Figure 9. AE hits before and after pore fluid decompression at $10 \mathrm{MPa}$ pore pressure and $175^{\circ} \mathrm{C}$ temperature condition at 20 MPa coinciding with spikes in AE hits from approximately 141.5s.

At $50 \mathrm{MPa}$ confining pressure and a pore pressure of $19.2 \mathrm{MPa}$, the rapid pore fluid venting at $93.8 \mathrm{~s}$ coincides with $\mathrm{AE}$ count rate of approximately 450 counts $/ 0.1$ milliseconds (Figure 10) by 94.1s. The elevated AE hit rate persists from this point to the end of the recording at $98 \mathrm{~s}$, but with a clearly underlying decrease in the event rate when the 'spikes' in activity are considered. Pore pressure again remains elevated at approximately $0.8 \mathrm{MPa}$ before decreasing to ambient pressure from approximately at $95 \mathrm{~s}$. Although not as clear as previous data (Fig 8 and 9), the AE hit rate also decreases by this time, and remains at a background level of 20-50 counts/s from 95s, once the periodic 'spikes' in AE are neglected. As before, we note that axial strain remains constant after pore fluid decompression, similar with the other venting experiments, and indicating minimal to no movement in the deformed sample. 

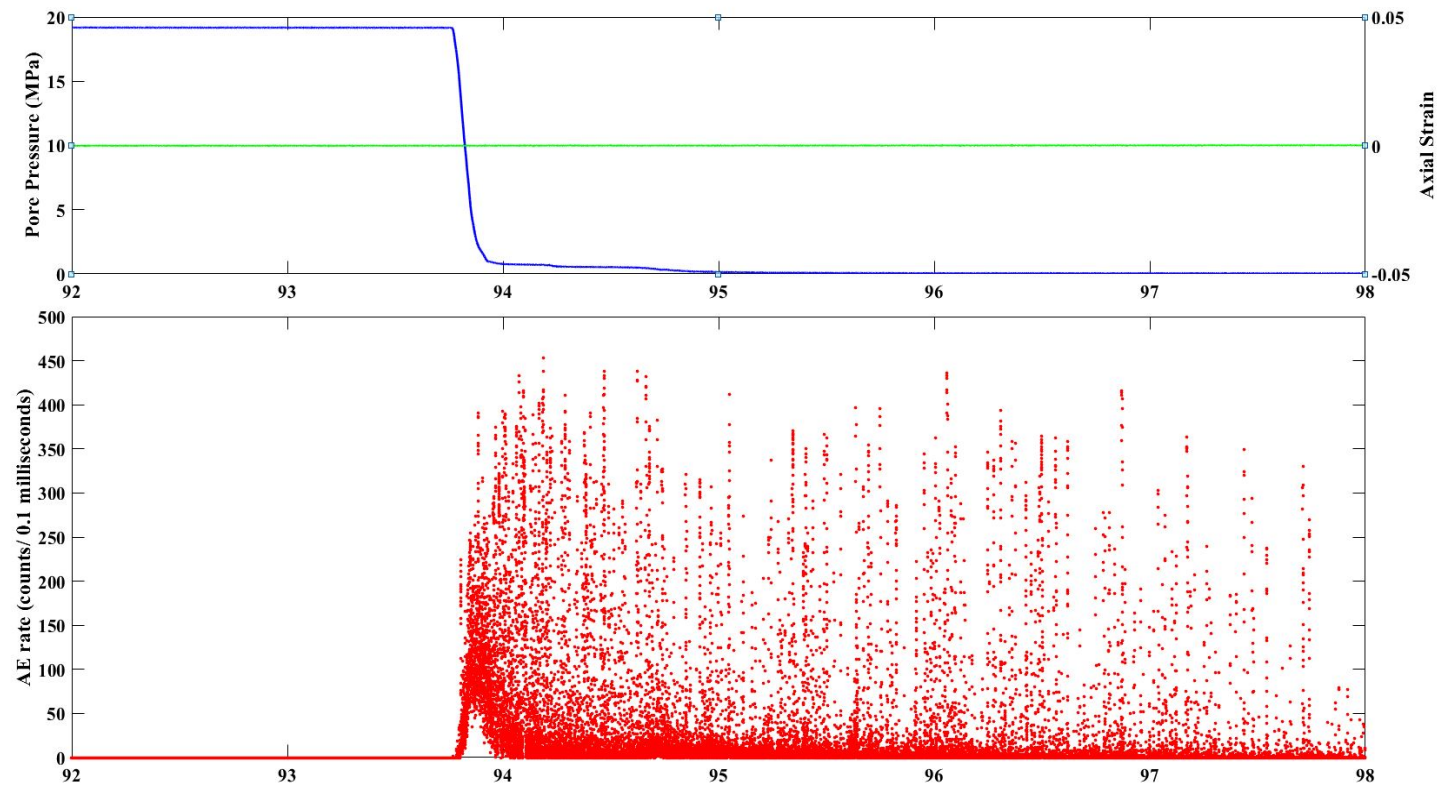

Figure 10. AE hits before and after pore fluid decompression at $19.2 \mathrm{MPa}$ and $175^{\circ} \mathrm{C}$ temperature condition and $50 \mathrm{MPa}$ confining pressure. Pore fluid pressure briefly stays at $0.8 \mathrm{MPa}$ after venting from 94 to $95 \mathrm{~s}$.

\section{Discussion and Conclusions}

Seismic velocities are commonly utilized to infer the state of material as a response to changing pressure and temperature conditions (e.g. Nasseri et al., 2004; Benson et al., 2008). Development of secondary structures, both macro and micro, are known to significantly influence $\mathrm{P}$ and S-wave velocities and are thus useful in energy resources exploration (e.g. Nara et al., 2011; Vinciguerra et al., 2005). Experiments carried out on andesite and volcaniclastic rock samples highlight the sensitivity of the seismic properties to macro and micro-crack opening and closing as a result of progressing pressure conditions. At the early stage of deformation where crack closure and compaction is dominant, $\mathrm{P}$ and $\mathrm{S}$-waves exhibit increasing trends that suggest sample stiffening. Conversely, crack propagation leading to failure and sample deformation is marked by large reduction in velocities in both andesite and the volcaniclastic rock.

Using elastic wave velocity data, dynamic material parameters are also calculated. This is useful, as these parameters are often more sensitive to environmental effects and fractures than elastic wave data alone. However, we do also note that dynamic elastic constants may differ to static constants as calculated using direct mechanical means (e.g. Heap et al., 2009). In general, however, the development of fracture due to applied stress decreases dynamic material 
447 parameters, with the exception of Poisson's ratio which increases. The application of 448 subsequent effective pressure increases both P-wave and S-wave velocities and elastic 449 properties, again with the exception of Poisson's ratio. Of the three elastic properties, bulk 450 modulus is particularly sensitive to damage formation. This is consistent with previous studies 451 that examined dynamic moduli in different rock types subjected to high temperature and 452 pressure conditions that result in the formation of both macro and micro fractures (e.g. Ayling 453 et al., 1994; Heap et al., 2009; Blake and Faulkner, 2015).

The use of dynamic elastic parameters aside from the conventional velocity models are 456 highlighted further on the seismic data gathered from SNGP. As shown in figure 11, seismic tomography results allowed examination and correlation of velocity models and other elastic parameters to subsurface data from a drilled well. Permeable zones are encountered below the production casing shoe (PCS) from 250 to 0 meters and from -300 to -500 meters elevation.

460 These zones of high fluid flow coincide with relatively low Vs from 2 to $2.5 \mathrm{~km} / \mathrm{s}$ and 461 transitioning Poisson's ratio values from 0.15 to 0.3 . The permeable zones are separated by an 462 approximately 300 meters thick layer with a different seismic attribute, having relatively high 463 Vs from 2.5 to $3 \mathrm{~km} / \mathrm{s}$ and reduced Poisson's ratio of around 0.1 . This horizon of absent 464 permeability and increased S-wave velocity suggest that the encountered formation is 465 competent and without fracturing. The thick zone of low Vs (around $1.5 \mathrm{~km} / \mathrm{s}$ ) and high 466 Poisson's ratio $(>0.3)$ above the PCS or within the closed-off section of the well likely 467 represents the cap rock of the geothermal system consisting mainly of low permeability but 468 highly porous clay minerals.

Permeability at depth in SNGP is reported to be controlled mainly by faults and fractures 471 based on well data (Pastoriza, 2017). These fractured formation or zones of high fluid flow can 472 be identified using velocities and elastic parameters which, under laboratory setting, exhibit 473 reduction with fracture development (except Poisson’s Ratio). 


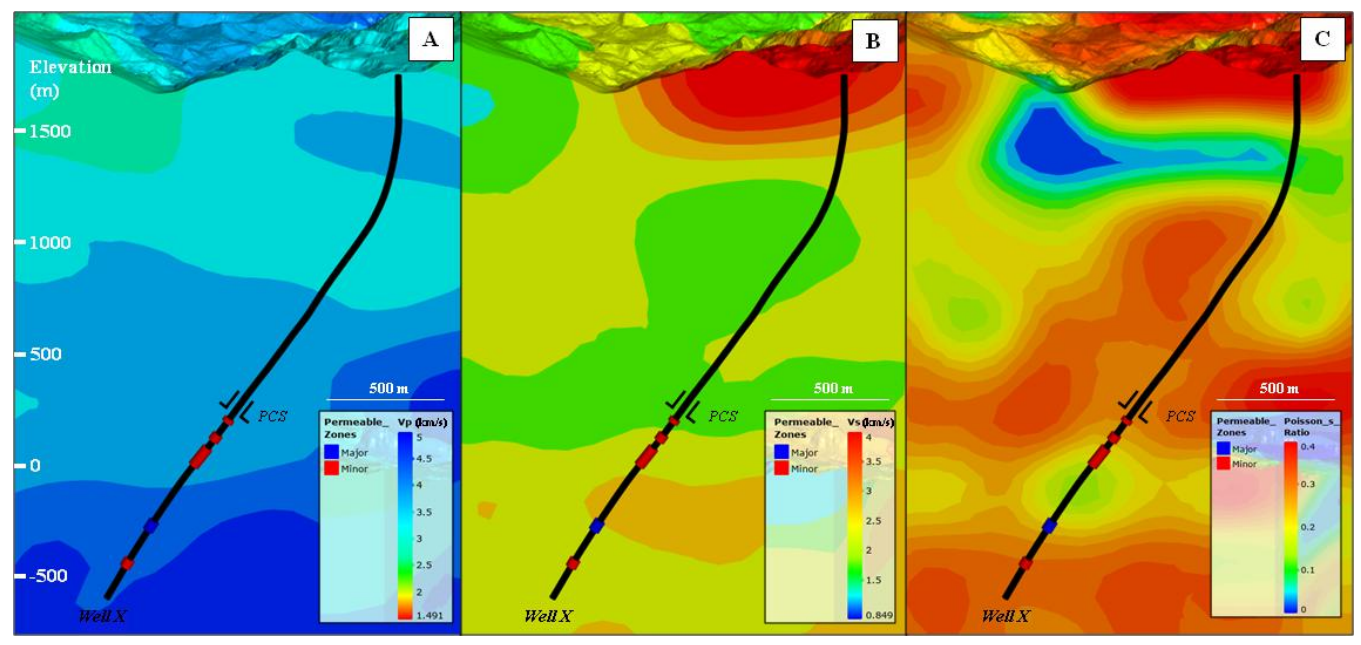

Figure 11. Vp (A), Vs (B) and Poisson's ratio (C) models derived from field seismic data in SNGP. Also shown is a drilled well in the area (Well $X)$ with permeable zones encountered (red and blue line along the well track) and the production casing shoe (PCS) which marks the start of the open-hole section of the well.

Using the measured steady state flow across the generated shear damage zone, we have applied a set of fixed-thickness 'slots' $(2-10 \mathrm{~mm})$ and the post-test length and width of the fracture, to calculate an effective permeability using equation (1). As shown in figure 12, SNA samples develop an effective permeability at $5 \mathrm{MPa}$ ranging from $2.7 \times 10^{-15}(10 \mathrm{~mm})$ to $2.7 \times 10^{-}$ ${ }^{14} \mathrm{~m}^{2}(2 \mathrm{~mm})$, decreasing to between $6.0 \times 10^{-16}$ to $6.0 \times 10^{-17} \mathrm{~m}^{2}$ at $30 \mathrm{MPa}$. For SNV, the fracture permeability ranges from $3.95 \times 10^{-15}(10 \mathrm{~mm})$ to $3.95 \times 10^{-14} \mathrm{~m}^{2}(2 \mathrm{~mm})$ at $5 \mathrm{MPa}$ to less than $1.0 \times 10^{-15} \mathrm{~m}^{2}(10 \mathrm{~mm})$ at $30 \mathrm{MPa}$ confining pressure. The lower overall permeability (both in terms of effective permeability model and raw flow rate data) of SNA compared to SNV is clearly evident. In addition, SNA data show a faster rate of decrease at lower pressures (5 to 15 $\mathrm{MPa}$ ). This is a common trend in freshly fractured rocks with low background permeability (e.g. Benson et al., 2006). With increasing pressure, the planar fractures are easily closed with application of confining pressure, resulting in significant reduction in fluid flow. In comparison, the higher porosity of the SNV sample has the effect of smoothing out the decrease in flow rate over the same period (5-15 MPa) whilst also providing an elevated background flow rate due to the more distributed nature of the flow which is not constrained to the damage zone. This is consistent with data from Seljadur Basalt (Nara et al., 2011) showing that while both macrofractures and micro-cracks contribute heavily to permeability at low confining pressures, microcracks tend to dominate at higher confining pressures as macro-fractures are easily closed and restrict fluid movement. 


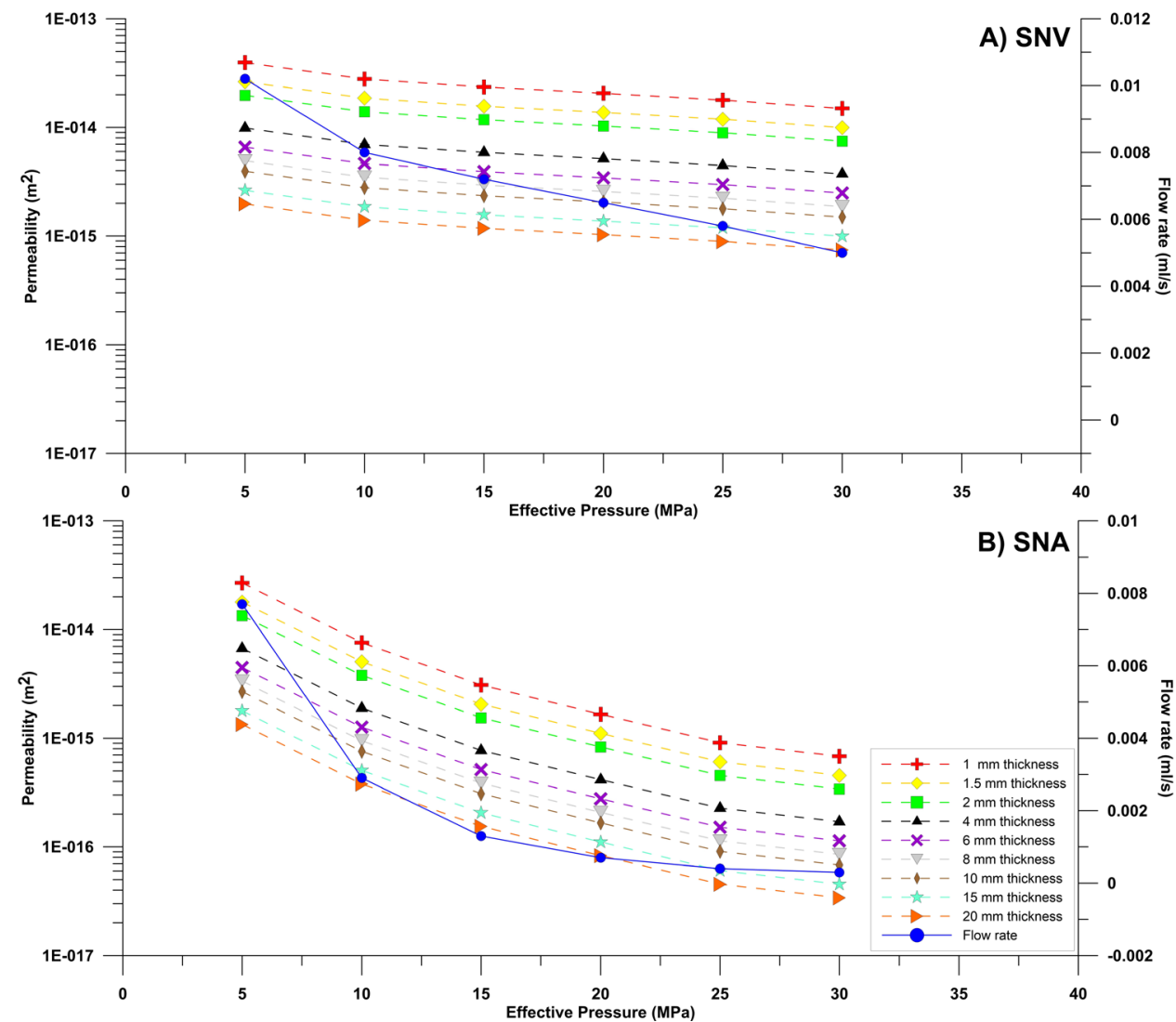

Figure 12. Effective permeability as a function of effective confining pressure after failure (fracture formation) in porous volcaniclastic rock of $12 \%$ (SNV, panel A) and non-porous andesite of $1 \%$ porosity (SNA, panel B)

We further note (Fig. 12) that a simple model of the changing fracture thickness does not match the change in the flow rate data. This suggests a more complex control on overall permeability (flow rate), such as crack and fracture closure and pore collapse (e.g. Benson et al., 2006; Baud et al., 2012). The exception is the SNA data at pressures higher than approximately $15 \mathrm{MPa}$, which matches well to a fracture damage zone of $20 \mathrm{~mm}$ thickness from pressures between 15-20 MPa, suggesting that for initially low porosity rock, the geometry of freshly generated damage zone is not altered significantly by application of pressure. Above $20 \mathrm{MPa}$, the decreasing fracture thickness then exerts the key influence on the still-reducing fluid flow in the sample. Reversing this analysis, by setting a constant damage zone permeability of $10^{-15} \mathrm{~m}^{2}$, illustrates the effect (Figure 13) with SNV showing a constant decrease in effective damage zone thickness from 10-15 MPa effective pressure whereas for SNA the decrease is very low. This is important, as high temperature geothermal systems are often found situated in tectonically active regions and in volcanic complexes, relying on faults for permeability and abnormally high geothermal gradients for heat flux. This, together with 
515 resource development activities such as fluid extraction and injection, makes such systems 516 dynamic and prone to changes in a relatively short period of time, allowing a significant 517 secondary permeability to be stimulated. As highlighted in our data, changes in the rock 518 properties may be inferred from a variety of seismic attributes (Bulk and Young's modulus, 519 Poisson's ratio, and AE). We find that these are often more sensitive that elastic wave velocity 520 alone, revealing that high fracture permeability at low confining pressure coincides with 521 significant reduction in seismic attributes with the exception of Poisson's ratio. Conversely, 522 reduction in permeability by fracture closure and material stiffening results in a decrease in 523 Poisson's ratio but increase in bulk modulus and Young's modulus.

525

526

527

528

529

530

531

532

533

534

535

536

537

538

539

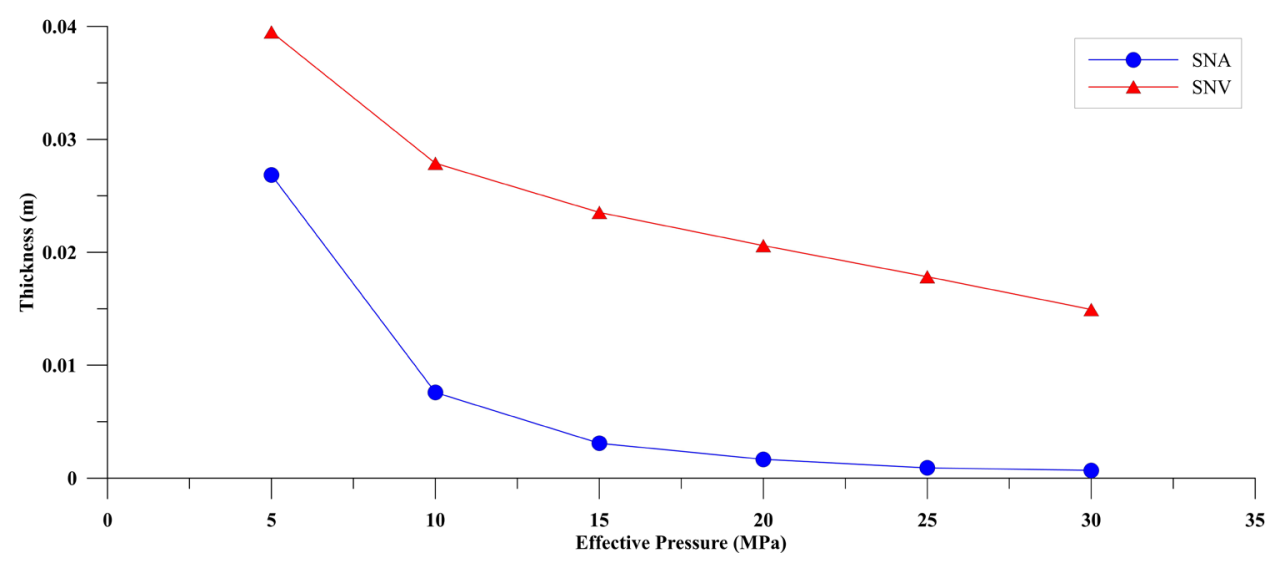

Figure 13. Apparent fault zone thickness as a function of effective confining pressure after failure (fracture formation) for a constant permeability of $1 \times 10^{-15} \mathrm{~m}^{2}$.

Fluid flow is known to generate passive seismicity, and in many cases, this has been the cause of significant geohazard (e.g. Giardini, 2009; Bachmann et al., 2012) especially if unknown faults are present in the rock mass. To further develop this, we conducted a short series of tests focussing on the fluid-rock interaction to induce seismic swarms at elevated temperatures across a range of confining pressures at relevant geothermal conditions (Figures 8-10). During our simulations a prominent swarm in AE is generated at the moment of pore pressure release with the AE broadly increasing with pore pressure. This is consistent with similar experiments (e.g. Benson et al., 2008; Benson et al, 2015; Fazio et al., 2019) which have linked fluid-rock interaction in fracture damage zones to swarms of AE activity due to fluid turbulence. In addition, at high temperatures the transition of water into steam (during the pressure release) has been linked to AE swarms at a lower characteristic frequency compared 
540 to room temperature control experiments (e.g. Benson et al., 2015). This is seen in our 541 experiments using the same protocol (Fazio et al., 2017) whereby pore pressure data in all experiments stabilises briefly at approximately $0.8 \mathrm{MPa}$ during the swarm duration; this

543 corresponds to the water to steam transition at $175^{\circ} \mathrm{C}$ following the boiling point pressure curve, as used in the experiments and consistent with geothermal reservoir conditions using a two-phase fluid. This suggests that geothermal extraction at lower depths $(>2 \mathrm{~km})$ is more likely to generate seismicity and potential instability in the local rock mass, such as via the reactivation of critically stressed faults and fractures. Fault reactivation has been documented to occur not just by fluid pressure increase, but by steam as well (Romero et al., 1995).

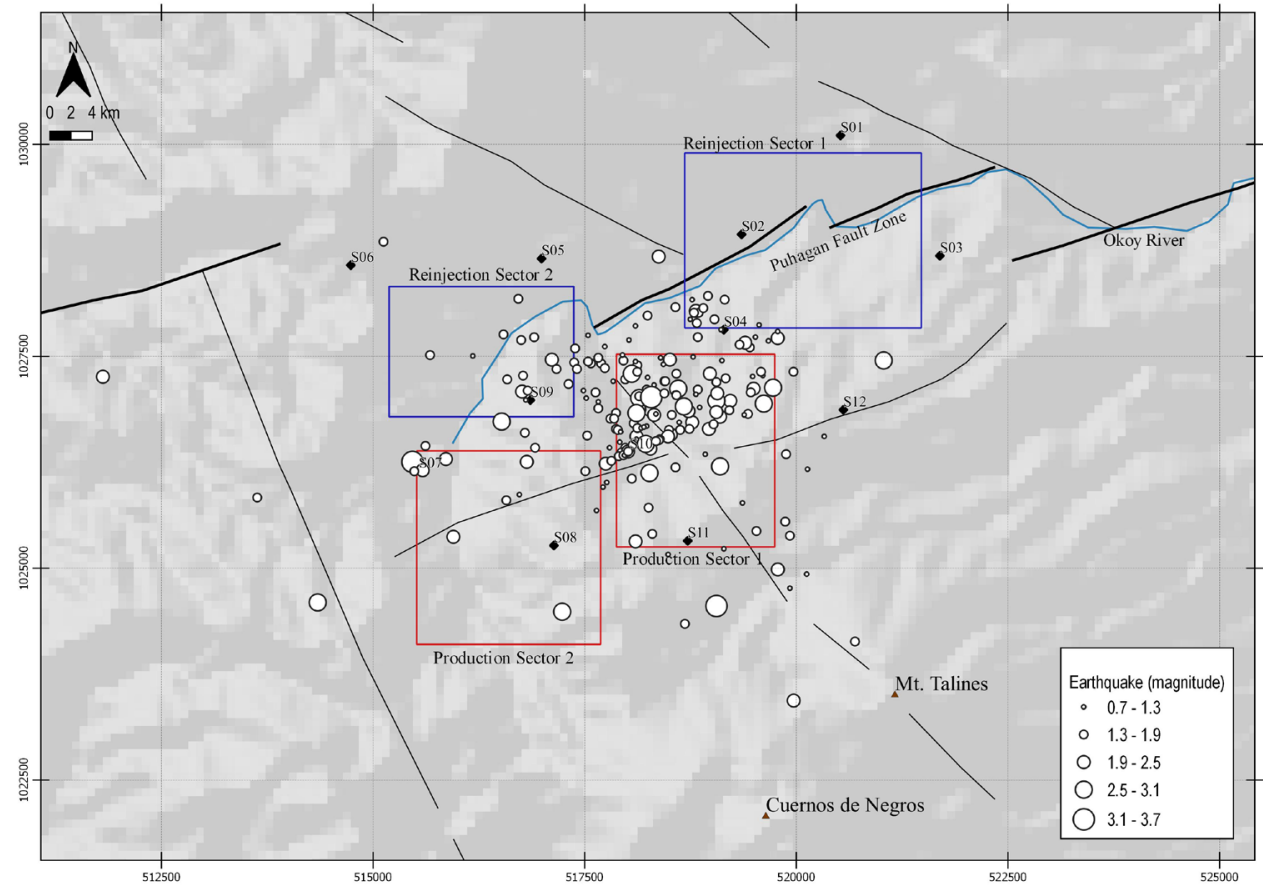

Figure 14. Recorded microearthquakes in SNGP after 6 months of data gathering (white circle). The production (red rectangle) and reinjection (blue rectangle) sectors are also shown.

555 Actual field data from SNGP highlights the effect of fluid extraction to seismicity. As shown

556 in figure 14, most earthquake epicentres are found south of the Okoy River where the 557 production sectors are situated. These earthquakes have magnitude values ranging from $<1$ to 558 3.7. Conversely, earthquake occurrences at the reinjection sectors were minimal. The contribution of injection activities to seismicity is well understood in geothermal fields, albeit 
560 in Enhanced Geothermal Systems (e.g. Cuenot et al., 2008; Horalek et al., 2010). This is caused

561 by pore fluid pressure increase, which reduces the effective normal stress that locks faults and 562 fractures and drives these critically stressed structures to exceed its failure shear stress and 563 promotes movement. Another mechanism from which earthquakes are generated is by hydraulic

564 fracturing that creates tensile cracks when the minimum stress is exceeded. However, seismic 565 data from a naturally permeable and convective geothermal system (SNGP) suggests that 566 injection of fluids has minimal effect on overall seismicity, implying further that fluid injection 567 pressure is below the needed pressure level to induce fault movement and generate fresh cracks. 568 Production activities appear to have more impact on the seismicity of SNGP than fluid injection.

569

570

571

572

573

574

575

576

577

578

579

580

581

582

583

584

585

586

587

588

589

590

Monitoring of earthquakes in oil and gas fields reveals that production induced seismicity is associated with collapse and compaction of void spaces (Doglioni, 2018) and normal fault activation, triggered by extraction of fluids and reduction in failure criterion (e.g. Zoback and Zinke, 2002; Doglioni, 2018). This mechanism of normal faulting and compaction appears to occur in the production sector of SNGP as a response to long period of fluid extraction, reflected on the location alone of recorded microearthquakes. However, a significant difference is observed between the two production sectors, with sector 1 exhibiting very high seismicity than sector 2 (Figure 14). This is possibly explained by the difference in pressure conditions (Malate et al., 2008), subsurface lithology (Rae et al., 2004) and length of production history, with sector 1 producing a decade earlier. Haug et al., (2017) have shown that normal faulting as a response to fluid extraction can be influenced by several factors such as the character of the fault (dip and throw), thickness and depth of the reservoir where fluids are extracted and geomechanical properties of the surrounding rocks.

Seismicity in SNGP can be attributed to normal faulting and collapse mechanisms that generate earthquakes (Bromley et al., 1987; Sewell et al., 2015; Sherburn et al., 2015). However, based on the laboratory experiments conducted in this study, rapid fluid movement and phase change can also contribute to the seismicity of the field. Experiments carried out in the laboratory shows that AEs are generated with pore fluid venting without deformation in the sample. As shown in figures 8, 9 and 10, contraction along the axial length of the samples did not occur with the decompression of pore pressure, reflected on unchanged axial strain across 
591 all the phase 2B experiments. This suggests that aside from fault movement and reservoir

592 compaction due to fluid extraction, the reported expansion of the two-phase zone (e.g. Malate

593 and Aqui, 2010) in the SNGP affects seismicity.

We conclude that $\mathrm{P}$ and $\mathrm{S}$ wave velocities and calculated elastic attributes such as Poisson's ratio, bulk and Young's moduli are sensitive to pressure changes and can be used to infer the state of material at depth (e.g. Blake and Faulkner, 2020). The formation of shear fractures that weakens the material decreases the attributes while increasing pressure conditions that strengthen the material via fracture closure increases the overall properties (Fig. 4, 6). We also note that increasing depth of burial, simulated by increasing pressure conditions, consistently

601 reduces fluid flow. Given the protocol used for generating the samples, the pore space is likely

602 to comprise of both a background (or primary) porosity inherent to the material, as well as the

603 fracture damage zone generated due to the fault (secondary porosity). As shown in figure 13, 604 the sample with lower initial porosity (SNA) shows a faster apparent fracture thickness 605 reduction within the first few MPa of effective pressure, consistent with flow dominated by a 606 single larger structure (fracture). This is consistent with recent work suggesting that 607 permeability reduction due to increased pressure may show lesser effect on geothermal 608 reservoirs that rely on both primary and secondary structures (e.g. Cant et al., 2018). Finally, 609 we conclude that AE may be directly generated through fluid movement and phase change at 610 temperature conditions consistent with those found in geothermal reservoirs. The extraction of 611 large quantities of fluids under high temperature is likely to contribute to the overall seismicity 612 in a region, in addition to that generated from fracture development related to fluid injection 613 and fault movement. Although not the focus of this study, monitoring of geothermal reservoirs 614 with seismic sensors (AE in the laboratory) has the potential to resolve both the 4D source and 615 character of the event (e.g. source mechanism, frequency vs magnitude). Larger scale 616 implementation of this would therefore be of benefit in understanding associated geohazards in 617 high temperature geothermal fields.

618 


\section{References}

622 Aurelio, M.A., Pena, R.E., Taguibao, K.J.L.: Sculpting the Philippine archipelago since the Cretaceous through rifting, oceanic spreading, subduction, obduction, collision and strike-slip faulting: Contribution to IGMA5000. Journal of Asian Earth Sciences, Vol. 72, (2013), 102 107, doi: 10.1016/j.jseaes.2012.10.007.

Ayling, M.R., Meredith, P.G., Murrell, S.A.F.: Microcracking during Triaxial deformation of Measurements on Dry Rocks. Tectonophysics, 245, (1995), 205-221, doi: 10.1016/00401951(94)00235-2.

Bachmann, C.E., Wiemer, S., Goertz-Allmann, B.P., Woessner, J.: Influence of pore-pressure on the event-size distribution of induced earthquakes. Geophysical Research Letters, 39, (2012), L09302, doi: 10.1029/2012GL051480.

Baud, P., Meredith, P., Townend, E.: Permeability evolution during triaxial compaction of an anisotropic porous sandstone. Journal of Geophysical Research, 117, (2012), B05203, doi: 10.1029/2012JB009176.

Benson, P. M., Meredith, P. G., \& Schubnel, A. (2006). Role of void space geometry in

Solid Earth, 111(12). https://doi.org/10.1029/2006JB004309

Benson P.M., Thompson, B.D., Meredith, P.G., Vinciguerra, S., Young, R.P.: Imaging slow 10.1029/2006GL028721.

656 Birch F.: The velocity of compressional waves in rocks to 10 kilobars: 1. Journal of Geophysical 
659 Blake, O.O., Faulkner, D.R.: The Effect of Fracture Density and Stress State on the Static and 660 Dynamic Moduli of Westerly Granite. Journal of Geophysical Research: Solid Earth, 121, 661 (2016), 2382-2399, doi: 10.1002/2015JB012310.

662

663

664

665

666

667

668

669

670

671

672

673

674

675

676

677

678

679

680

681

682

683

684

685

686

687

688

689

690

691

692

693

694

695

696

697

698

Blake, O.O., Faulkner, D.R.: Using Velocities, Density, and Bulk Modulus to Predict the Permeability Evolution of Microfractured Rocks. Rock Mechanics and Engineering. (2020), doi: $10.1007 / \mathrm{s} 00603-020-02163-7$

Bonner, B., Hutchings, L., Kasameyer, P.: A Strategy for Interpretation of Microearthquake Tomography Results in Salton Sea Geothermal Field Based upon Rock Physics Interpretations of State 214 Borehole Logs. Proceedings, Geothermal Resource Council Annual Meeting, San Diego, California (2006), doi: 10.5772/intechopen. 81226

Bromley, C.J., Pearson, C.F., Rigor, D.M., PNOC-EDC.: Microearthquakes at the Puhagan Geothermal Field, Philippines - A case of induced seismicity. Journal of Volcanology and Geothermal Research, 31, (1987), 293-311.

Browning, J., Meredith, P., Gudmundsson, A.: Cooling-dominated cracking in thermally stressed volcanic rocks. Geophysical Research Letter, 43, (2016), 8417-8425, doi: 10.1002/2016GL070532

Cant, J.L., Siratovich, P.A., Cole, J.W., Villenueve, M.C., Kennedy, B.M.: Matrix permeability of reservoir rocks, Ngatamariki geothermal field, Taupo Volcanic Zone, New Zealand. Geothermal Energy, 6, 2 (2018), doi: 10.1186/s40517-017-0088-6.

Castagna, A., Ougier-Simonin, A., Benson, P. M., Browning, J., Walker, R. J., Fazio, M., Vinciguerra, S: . Thermal damage and pore pressure effects of the brittle-ductile transition in Comiso limestone. Journal of Geophysical Research: Solid Earth, 123, (2018), doi: 10.1029/2017JB015105.

Cuenot, N., Dorbath, C., Dorbath, L.: Analysis of the Microseismicity Induced by Fluid Injections at the EGS Site of Soultz-sous-Forets (Alsace, France): Implications for the Characterization of the Geothermal Reservoir Properties. Pure Applied Geophysics, 162, (2008), 797-828, doi 10.1007/s00024-008-0335-7.

De Siena L., Thomas, C., Waite, G., Moran, S., Klemme, S.: Attenuation and scattering tomography of the deep plumbing system of Mount St. Helens. Journal of Geophysical Research, 119, (2014a), 8223-8238, doi: 10.1002/2014JB011372

Doglioni, C.: A classification of induced seismicity. Geoscience Frontiers, (2018), 9, 19031909, doi: 10.1016/j.gsf.2017.11.015 
Fazio, M., Benson, P.M., Vinciguerra, S.: On the generation mechanisms of fluid-driven seismic signals related to volcano-tectonics. Geophys. Res. Lett., 44, (2017), doi: 10.1002/2016GL070919

Fazio, M., Alparone, S., Benson, P. M., Cannata, A., \& Vinciguerra, S. (2019). Genesis and mechanisms controlling tornillo seismo-volcanic events in volcanic areas. Scientific Reports, 9(1). https://doi.org/10.1038/s41598-019-43842-y

Gehne, S., Benson, P. M., Koor, N., Dobson, K. J., Enfield, M., Barber, A.: Seismo-Mechanical Insights. Journal of Geophysical Research: Solid Earth, 124(9), (2019), 9562-9579, doi: 10.1029/2019JB017342.

Geraud, Yves, et al.: Physical properties of fault zones within a granite body: example of the Soultz-sous-Forêts geothermal site. Comptes Rendus Geoscience, 342,7-8 (2010): 566-574.

Giardini, D.: Geothermal quake risks must be faced. Nature, (2009), 462, 848-849, doi: 10.1038/462848a.

Harnett, C.E., Benson, P.M., Rowley, P., Fazio, M.: Fracture and damage localization in volcanic edifice rocks from El Hierro, Stromboli and Tenerife. Nature Scientific Report, 8, (2018), 1942, doi: 10.1038/s41598-018-20442-w.

Haug, C., Nüchter, J.A., Henk, A.: Assessment of geological factors potentially affecting production-induced seismicity in North German gas fields, Geomechanics for Energy and the Environment, (2018), 16, 15-31, doi: 10.1016/j.gsf.2017.11.015.

736

737

Heap, M.J., Vinciguerra, S., Meredith, P.G.: The Evolution of Elastic Moduli with Increasing Crack Damage during Cyclic Stressing of a Basalt from Mt. Etna Volcano, Tectonophysics,

739 Hutchings, L., Bonner, B., Jarpe, S., Singh, A.: Micro-earthquake Analysis for Reservoir 740 Properties at the Prati-32 Injection Test, The Geysers, California, Proceedings, Fortieth 
Workshop on Geothermal Reservoir Engineering, Stanford University, Stanford, California (2015), doi: 10.13140/2.1.2474.2404.

Hochstein, M.P.: "Classification and assessment of geothermal resources." In: Dickson MH and Fanelli M (eds) Small geothermal resources, UNITAEWNDP Centre for Small Energy Resources, Rome, Italy, (1990), 31-59.

Horálek, J., Jechumtálová, Z., Dorbath, L.: Source mechanisms of micro-earthquakes induced in a fluid injection experiment at the HDR site Soultz-sous-Forêts (Alsace) in 2003 and their temporal and spatial variations, Geophys $J$ Int., (2010), 181(3), 1547-1565, doi: 10.1111/j.1365-246X.2010.04506.X

Jarvis, A., Reuter, H.I., Nelson, A., Guevarra, E.: Hole-filled seamless SRTM data V4, International Centre for Tropical Agriculture (CIAT), (2008), available from http://srtm.csi.cgiar.org.

Julian, B.R., Foulger, G.R.: Improved Methods for Mapping Permeability and Heat Sources in Geothermal Areas Using Microearthquake Data, Proceedings, Thirty-Fifth Workshop on Geothermal Reservoir Engineering, Stanford University, Stanford, California (2010).

Julian, B.R., Foulger, G.R., Monastero, F.C., Bjornstad, S.: Imaging Hydraulic Fractures in a Geothermal Reservoir, Geophysical Research Letters, 37, (2010), L07305.

Kushnir, A.RL., Heap, M.J., Patrick Baud, P.: Assessing the role of fractures on the permeability of the Permo-Triassic sandstones at the Soultz-sous-Forêts (France) geothermal site, Geothermics, 74, (2018), 181-189.

Lockner, D., Byerlee, J., Kuksenko, V., Ponomarev, A., Sidorin, A.: Quasi-static fault growth and shear fracture energy in granite, Nature, 350, (1991), 39-42, doi: 10.1038/350039a0.

Malate, R.C.M., Aqui, A.R., Orizonte Jr., R.G.: Sustaining and Optimizing Steam Production in the Southern Negros Geothermal Production Field, Philippines, Proceedings of the $8^{\text {th }}$ Asian Geothermal Symposium, December 9-10, 2008.

Malate, R.C.M., Aqui, A.R.: Steam Production from the Expanded Two-Phase Region in the Southern Negros Geothermal Production Field, Philippines, Proceedings World Geothermal Congress 2010, Bali, Indonesia.

McLaskey, G.C., Lockner, D.A.: Preslip and Cascade Processes Initiating Laboratory Stick Slip, Journal of Geophysical Research: Solid Earth, 119, (2014), doi: 10.1002/2014JB011220. 
Nara, Y., Meredith, P.G., Yoneda, T., Kaneko, K.: Influence of Macro-fractures and Microfractures on Permeability and Elastic Wave Velocities in Basalt at Elevated Pressure, Tectonophysics, 503, (2011), 52-59, doi: 10.1016/j.tecto.2010.09.027.

Nasseri, M.H.B., Schubnel, A., Young, R.P.: Coupled Evolutions of Fracture Toughness and Elastic Wave Velocities at High Crack Density in Thermally Treated Westerly Granite, International Journal of Rock Mechanics and Mining Sciences, 44, (2004), 601-616, doi: 10.1016/j.ijrmms.2006.09.008.

Passelègue, F.X., Schubnel, A., Nielsen, A., Bhat, H.S., Deldicque, D., Madariaga, R.: Dynamic Rupture Processes Inferred from Laboratory Microearthquakes, Journal of Geophysical Research: Solid Earth, 121, (2016), doi: 10.1002/2015JB012694.

Pastoriza, L.R.: The geological characterisation and permeability evaluation of fractures in the Southern Negros Geothermal Field, Negros Island, Philippines, Doctoral Thesis, (2017), Doctoral Thesis, University of Durham, United Kingdom.

Pastoriza, L.R., Holdsworth, R.E., McCaffrey, K.J., Dempsey, E.: Tectonic Evolution of the Southern Negros Geothermal Field and Implications for the Development of Fractured Geothermal Systems, Geofluids, (2018), doi: 10.1155/2018/6025038

Rae, A.J., Cooke, D.R., Phillips, D., Yeats, C., Ryan, C., Hermoso, D.: Spatial and Temporal Relationships between Hydrothermal Alteration Assemblages at the Palinpinon Geothermal Field, Philippines: Implications for Porphyry and Epithermal Ore Deposits, Society of Economic Geologists, Special Publication, 2003.

Rae, A.J., Cooke, D.R., Phillips, D., Zaide-Delfin, M.: The nature of magmatism at Palinpinon geothermal field, Negros Island, Philippines: implications for geothermal activity and regional tectonics, Journal of Volcanology and Geothermal Research, vol. 129, no. 4, (2004), 321-342.

Romero, Jr., A.E., McEvilly, T.V., Majer, E.L., Vasco, D.: Characterization of the geothermal system beneath the Northwest Geysers steam field, California, from seismicity and velocity patterns. Geothermics, 24, (1995), 471-487, doi: 10.1016/0375-6505(95)00003-9.

Sewell, S.M., Cumming, W., Bardsley, C.J., Winick, J., Quinao, J., Wallis, I.C., Sherburn,S., Bourguignon, S., Bannister, S.: Interpretation of microseismicity at the Rotokawa Geothermal Field, 2008-2015. In: Proceedings World Geothermal Congress 19-25 April 2015, Melbourne, Australia. 
821 Sherburn, S., Bromley, C., Bannister, S., Sewell, S., Bourguignon, S.: New Zealand Geothermal 822 Induced Seismicity: an overview. Proceedings World Geothermal Congress 2015, Melbourne, 823 Australia

Siratovich, P. A., Heap, M.J., Villenueve, M.C., Cole, J.W., Reuschle, T.: Physical property 826 relationship of the Rotokawa Andesite, a significant geothermal reservoir rock in the Taupo 827 Volcanic Zone, New Zealand. Geothermal Energy, 2, (2014), doi: 10.1186/s40517-014-00108284.

829

830 Siratovich, P. A., Heap, M.J., Villeneuve, M.C., Cole, J.W., Kennedy, B.M., Davidson, J., 831 Reuschle, T.: Mechanical behaviour of the Rotokawa Andesites (New Zealand): Insight into 832 permeability evolution and stress-induced behaviour in an actively utilised geothermal 833 reservoir. Geothermics, 64, (2016), 163-179, doi: 10.1016/j.geothermics.2016.05.005.

834

835 Vinciguerra, S., Trovato, C., Meredith, P.G., Benson, P.M.: Relating seismic velocities, thermal 836 cracking and permeability in Mt. Etna and Iceland basalts. International Journal of Rock 837 Mechanics \& Mining Sciences, 42, (2005), 900-910, doi: 10.1016/j.ijrmms.2005.05.022.

Zoback, M.D., Zinke, J.C.: Production-induced normal faulting in the valhall and ekofisk oil 840 fields, Pure Appl Geophys (Pageoph), 159, (2002):403-420, the Geysers Geothermal Field, California. Geothermics, 23, (1994), 111-126, doi: 10.1016/0375-6505(94)90033-7. 